\title{
The Annual Cycle of SST in the Eastern Tropical Pacific, Diagnosed in an Ocean GCM*
}

\author{
WILLIAM S. KeSSLER \\ NOAA/Pacific Marine Environmental Laboratory, Seattle, Washington \\ LEWIS M. RothSTEIN \\ Graduate School of Oceanography, University of Rhode Island, Narragansett, Rhode Island \\ DAKe CHEN \\ Lamont-Doherty Earth Observatory, Columbia University, New York, New York
}

(Manuscript received 29 January 1997, in final form 21 July 1997)

\begin{abstract}
The annual onset of the east Pacific cold tongue is diagnosed in an ocean GCM simulation of the tropical Pacific. The model uses a mixed-layer scheme that explicitly simulates the processes of vertical exchange of heat and momentum with the deeper layers of the ocean; comparison with observations of temperature and currents shows that many important aspects of the model fields are realistic. As previous studies have found, the heat balance in the eastern tropical Pacific is notoriously complicated, and virtually every term in the balance plays a significant role at one time or another. However, despite many complications, the three-dimensional ocean advection terms in the cold tongue region tend to cancel each other in the annual cycle and, to first order, the variation of SST can be described as simply following the variation of net solar radiation at the sea surface (sun minus clouds). The cancellation is primarily between cooling due to equatorial upwelling and warming due to tropical instability waves, both of which are strongest in the second half of the year (when the winds are stronger). Even near the equator, where the ocean advection is relatively intense, the terms associated with cloudiness variations are among the largest contributions to the SST balance. The annual cycle of cloudiness transforms the semiannual solar cycle at the top of the atmosphere into a largely 1 cycle $\mathrm{yr}^{-1} \mathrm{variation}$ of insolation at the sea surface. However, the annual cycle of cloudiness appears closely tied to SST in coupled feedbacks (positive for low stratus decks and negative for deep cumulus convection), so the annual cycle of SST cannot be fully diagnosed in an ocean-only modeling context as in the present study. Zonal advection was found to be a relatively small influence on annual equatorial cold tongue variations; in particular, there was little direct (oceanic) connection between the Peru coastal upwelling and equatorial annual cycles. Meridional advection driven by cross-equatorial winds has been conjectured as a key factor leading to the onset of the cold tongue. The results suggest that the SST changes due to this mechanism are modest, and if meridional advection is in fact a major influence, then it must be through interaction with another process (such as a coupled feedback with stratus cloudiness). At present, it is not possible to evaluate this feedback quantitatively.
\end{abstract}

\section{Introduction}

The quest to understand the annual cycle of SST in the eastern equatorial Pacific has provided many investigators with fertile ground for thought and analysis. With a larger annual amplitude of SST than any region in the Tropics, east Pacific SST is thought to have a prominent effect on the annual march of seasonal climatology over the Americas. In addition, the observa-

* PMEL Contribution Number 1830.

Corresponding author address: William S. Kessler, NOAA/Pacific Marine Environmental Laboratory, 7600 Sand Point Way NE, Seattle, WA 98115.

E-mail: kessler@pmel.noaa.gov tion that the El Niño cycle often appears at a characteristic time of year has suggested the importance of a clear description of the factors influencing the annual cycle of SST. Unfortunately, it has often been shown that many if not most of the heat flux and ocean mixing and advection terms can be significant contributors to the near-surface annual cycle in this region, and the balance has proven hard to categorize straightforwardly. It is noteworthy that a great variety of model formulations, representing a wide range of seemingly disparate physical assumptions, have been at least partly successful in reproducing the annual cycle in this region, leading to the impression that fundamental aspects remain obscure and that our ability to convincingly model the phenomena is still in doubt. Because vertical entrainment is so important in this region of shallow thermocline but so difficult to quantify, it is unlikely that 


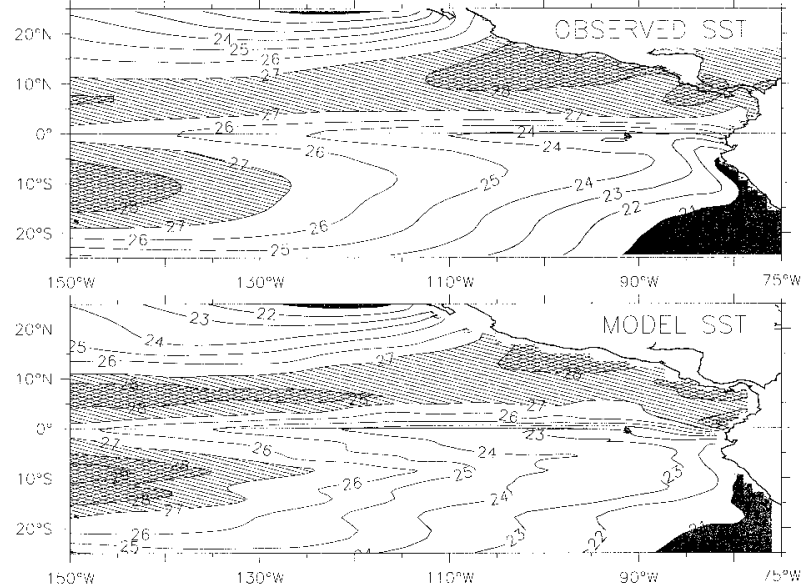

FIG. 1. Observed and modeled mean SST in the eastern tropical Pacific. Top: observed (Reynolds and Smith 1994) blended satellite product during 1984-93; bottom: model mean. The contour interval is $1^{\circ} \mathrm{C}$. Shading indicates SST less than $24^{\circ} \mathrm{C}$ (dark shading for SST less than $21^{\circ} \mathrm{C}$ ), and hatching indicates SST greater than $27^{\circ} \mathrm{C}$ (double hatching for SST greater than $28^{\circ} \mathrm{C}$ ).

better observations alone can settle the matter. Therefore, improvement and careful validation of models of the eastern Pacific is an obligatory task. While there is no doubt that the oceanic and atmospheric cycles are strongly coupled in this region, it is also clear that present models of both fluids have essential weaknesses, so successful coupled integrations may be difficult to achieve or interpret until we have a firm grasp of the complexities of the forced response within each fluid separately. The present paper continues this effort to understand and quantify the ingredients that make up the annual cycle of SST in the cold tongue, using an ocean model and available observations.

A review of the literature illustrates the range of processes that are thought to be important to the annual march. Among observational analyses, Hansen and Paul (1984) used drifting buoy time series to suggest that eddy equatorward transport of heat across the sharp SST front that forms the northern boundary of the cold tongue (Fig. 1) was comparable to the total shortwave flux. Bryden and Brady (1989) confirmed this result based on moored current meter observations. Enfield (1986) estimated a seasonal climatology of heat fluxes in equatorial boxes and found significant contributions from virtually all the heat flux terms. He suggested that the stronger winds in the second half of the year produced larger upwelling, zonal advection, and meridional (eddy) diffusion. This is consistent with results reported in the present paper. Hayes et al. (1991a) analyzed moored temperature and current observations during the El Niño-La Niña period 1986-88. Like Enfield, they found a very complex interaction among terms of the near-surface heat balance during this period but suggested that the largest terms were surface fluxes and downward heat flux (upwelling and entrainment). Mitchell and Wallace (1992) studied an average annual cycle of COADS surface observations and pointed to a major role for the meridional cross-equatorial wind. They argued that as the land surface north of the equator heats up in boreal spring, the associated convection produces large-scale southerly winds over the eastern $\mathrm{Pa}-$ cific. These winds drive northward cross-equatorial currents with upwelling just south of the equator (Philander and Delecluse 1983). Mitchell and Wallace (1992) suggested that cooling of the planetary boundary layer due to this upwelling results in locally rising surface pressure that reinforces the southerly winds and hypothesized that this cooling begins a coupled process leading to the annual onset of the cold tongue. Mitchell and Wallace (1992) looked only at surface observations and therefore could not evaluate whether the actual ocean currents were sufficient to generate the SST changes necessary to their hypothesis. An important motivation for the present paper was to understand the role of oceanic heat advection driven by the observed annual cycle meridional winds suggested by Mitchell and Wallace (1992).

Numerous ocean models of varying complexity have been used to interpret the cold tongue annual variability. Seager et al. (1988) found that a relatively simple reduced gravity model with linear dynamics but nonlinear thermodynamics could simulate many aspects of the observed SST. Gordon and Curry (1991) used an ocean GCM; their results showed that the ocean model could be very sensitive to small changes in the surface forcing functions. Chang (1993) argued that because the mixed layer in the eastern Pacific is thin, SST in this region tends to be in equilibrium with the heating. In agreement with the present results, Chang (1994), using models of intermediate complexity, found that mixed-layer entrainment (as simulated by Kraus-Turner physics where the mixed layer changes thickness due to buoyancy fluxes and stirring from the atmosphere) is a key element of SST change. Chang (1994) noted that although surface heat fluxes are dominant in the western equatorial Pacific and away from the equator, the dynamical effect of the wind (upwelling and vertical entrainment) is the physical process responsible for the westward propagation of the annual cycle of SST. Brady and Gent (1994) used an earlier version of the same model studied here (with a simpler mixed layer) and partitioned the mean annual heat flux into eddy transport, transport by the low-frequency horizontal circulation, and transport by the meridional overturning circulation. Only the last of these transports heat poleward. They found that seasonal variation of these fluxes depends not only on the strength of the associated currents, but also on lessobvious changes in the vertical temperature gradients. Koberle and Philander (1994) showed a balance in the eastern Pacific between upwelling versus surface fluxes. They noted that variations of cloudiness were important in the evaluation of the short- and longwave heat fluxes. 
Schneider (1998, manuscript submitted to J. Climate) emphasized the difference between solar forcing (which is semiannual near the equator) and ocean response, which is an integral of the forcing and thus enhances the low frequencies. Because of the low-pass filtering due to integration, even an extremely simple one-dimensional ocean need not have a dominant semiannual signal when forced with the observed, primarily semiannual, solar cycle.

Several modeling studies have begun to elucidate aspects of the air-sea coupling. Xie (1994) pointed out that since the mean ITCZ in the eastern Pacific is north of the equator, variations of solar heating there can force an annual cycle of meridional winds on the equator even though the local equatorial solar cycle is semiannual. He contended that direct solar forcing has little effect on equatorial SST, but instead the annual cycle is determined by the cross-equatorial winds through vertical mixing and evaporation. $\mathrm{Li}$ and Philander (1996) also argued for the importance of the mean asymmetry of the ITCZ and were able to simulate a reasonable coupled annual cycle in the cold tongue in a model with a solar forcing annual cycle strictly antisymmetric about the equator (hence with no variation of solar radiation at the equator). However, their model only developed the correct amplitude of SST when a positive feedback between cold SST and stratus clouds was included. This cloud feedback induced an annual cycle of net shortwave radiation received at the equatorial sea surface. On the other hand, Giese and Carton (1994) used a coupled model that did not develop enough stratus but still were able to simulate the proper phase of cold tongue SST. They conducted experiments in which the solar forcing was modified in various ways; in particular, they showed that if the solar year was lengthened to 18 months, this might allow the Southern Hemisphere ocean to warm sufficiently that the ITCZ could cross the equator and produce a semiannual cycle of equatorial SST.

In sum, the many studies to date have suggested a wide variety of sometimes-antithetical mechanisms that might contribute to the observed SST annual cycle in the eastern tropical Pacific. Results of the present paper indicate a key role for the annual cycle of cloudiness, particularly in connection with the stratus decks and therefore point to the essential coupled nature of the problem. We will also argue that the annual cycles of equatorial upwelling and meridional eddy diffusion (due to tropical instability waves) act to oppose and largely cancel each other in the surface layer temperature balance. Thus, the overall role of the ocean is smaller than it would appear from the values of the individual oceanic terms, and this net cancellation might account for the rather disparate results found in the studies cited above.

There is some ambiguity in defining the "eastern tropical Pacific." For the purposes of this study, we would like to identify a region affected by the monsoonal circulations due to the American continent and distinct from the very long zonal scales of the central basin that are less affected by boundaries. For a number of reasons, the eastern boundary of our region is relatively easy to specify as $90^{\circ} \mathrm{W}$, which is approximately the eastern limit of mean easterly trade winds. Farther east, winds blow nearly parallel to the coast and into the Gulf of Panama. Perhaps coincidentally, $90^{\circ} \mathrm{W}$ is also a minimum of amplitude of the annual cycle of zonal winds and a longitude of sharp phase change of this quantity. In our model, the eastern limit of the equatorial undercurrent and strong equatorial upwelling occurs at about $90^{\circ} \mathrm{W}$, due to this pattern of zonal winds. The eastward zonal pressure gradient that characterizes most of the Pacific also changes sign east of $90^{\circ} \mathrm{W}$ in the model, and terms of the momentum equation closer to the coast form a completely different balance. For these reasons, $90^{\circ} \mathrm{W}$ is an appropriate boundary that separates regions with quite dissimilar forcing and dynamical characteristics.

The western limit of the region is harder to define, and our choice of $120^{\circ} \mathrm{W}$ is somewhat more arbitrary. $120^{\circ} \mathrm{W}$ is roughly the western edge of the stratus cloud decks that we will show are a crucial aspect of the thermodynamics. The annual cycle of cloud cover has similar phase east of $120^{\circ} \mathrm{W}$ and relatively sharp phase change to the west as the dominant cloud type changes. The result of this strong cloud variability in the east is that the annual cycle of net solar radiation received at the sea surface is dominated by the 1 cycle $\mathrm{yr}^{-1}$ harmonic from about $85^{\circ} \mathrm{W}$ to $110^{\circ} \mathrm{W}$ but has a large semiannual component further west. East of $120^{\circ} \mathrm{W}$, the mean meridional wind is larger than the mean zonal wind; this is also the westernmost point where the annual variance of zonal wind is smaller than that of the meridional component. Examining the model fields, we find that for many quantities the region $90^{\circ}-120^{\circ} \mathrm{W}$ has reasonably homogeneous variance. Considering all these features, we have chosen to define the region between $90^{\circ}$ and $120^{\circ} \mathrm{W}$ as the "eastern tropical Pacific" in this paper and will present several quantities as meridional sections averaged over this longitude range.

\section{Model and data used to study the cold tongue}

\section{a. Model formulation}

The tropical upper ocean GCM used in this study consists of two physical components: a sigma-layer, tropical primitive equation general circulation model developed by Gent and Cane (1989), with the "hybrid" mixed layer formulation developed by Chen et al. $(1994 a, b)$ as its upper layer. The entire model domain is the upper layer of a reduced-gravity ocean, assumed to overlie an infinitely deep, motionless lower layer. There is thus no bottom topography. The sigma vertical coordinate divides the upper ocean below the mixed layer into a specified number of layers (here eight) that vary their thickness in space and time, but the ratio of 
sigma layer thicknesses remains fixed. Layer interfaces are not material surfaces and are rearranged at each timestep. First, at each grid point, the mixed-layer depth is predicted (by the mixed-layer model described below), and the total model thickness is adjusted by the sum over all sigma layers of the mass convergences in the preceding timestep. Then, the thickness of each layer for the present timestep is found by dividing this total thickness according to the fixed sigma ratios. This sequence is repeated at each timestep. One advantage of this vertical coordinate is its computational efficiency. Second, since the upper sigma levels follow the (time and space varying) base of the mixed layer, the vertical resolution is fine precisely where it is needed: right below the mixed layer. This overcomes one of the major disadvantages of level models, which need high resolution over the entire range of mixed layer variation. The purpose of the sigma vertical coordinate is to provide high resolution just below the mixed layer while requiring relatively few vertical layers, with the result that this model is up to an order of magnitude faster than other popular GCMs with similar temporal and spatial resolution.

The hybrid mixing scheme of Chen et al. (1994a) defines a turbulent boundary layer that exchanges momentum and heat with the atmosphere at its surface and with the thermocline by entrainment at its base. The three major physical processes of upper-ocean turbulent mixing are explicitly simulated. Mixed layer entrainment and detrainment are related to wind stirring and surface buoyancy (heat) flux using a bulk mixed layer (Kraus and Turner 1967) model, shear flow instability is accounted for by partial mixing controlled by the gradient Richardson number, and an instantaneous adjustment parameterizes free convection (e.g., Price et al. 1986). In essence, this combines the most physically realistic features of a bulk mixed layer model with those of an instability mixing model (Chen et al. 1994a).

The present model domain is the equatorial Pacific with solid walls at $30^{\circ} \mathrm{S}$ and $30^{\circ} \mathrm{N}$ and no opening through the Indonesian Archipelago, but otherwise realistic east and west coasts. A stretched grid is used with spacing $40 \mathrm{~km}$ (meridional) by $125 \mathrm{~km}$ (zonal) in the cold tongue region. The timestep is $1 \mathrm{~h}$. The model is initialized with the Levitus (1982) mean temperatures (and zero currents). Relaxation to the Levitus annual cycle climatological temperatures becomes progressively stronger poleward of $\pm 20^{\circ}$ latitude to suppress coastal Kelvin waves that would otherwise contaminate the solution given these unrealistic poleward boundaries. In the present formulation, the equation of state is a linear function of temperature, with no effect of salinity, although it has been suggested (Murtugudde and Busalacchi 1998, manuscript submitted to J. Geophys. Res.) that variations of salinity may be an important aspect in the eastern tropical Pacific.

During model runs, we distinguish and store seven terms of the temperature balance, including three ad- vection terms, three surface flux terms, and a term representing vertical mixing. The surface layer SST equation can be written (Gent and Cane 1989)

$$
\begin{gathered}
\rho C_{p} h\left(\frac{\partial T}{\partial t}+u \frac{\partial T}{\partial x}+v \frac{\partial T}{\partial y}+\frac{w}{h} \frac{\partial T}{\partial s}\right) \\
=\frac{d Q}{d s}=Q_{\mathrm{sw}}+Q_{\mathrm{e}}+Q_{\mathrm{w}, s}+Q_{\mathrm{m}},
\end{gathered}
$$

where $\rho$ is density, $C_{p}$ is the heat capacity of seawater, $h$ is the upper-layer thickness, $T$ the mixed layer temperature (SST), and $s$ the vertical sigma coordinate. For simplicity, the first three terms on the right-hand side, consisting of the shortwave flux $Q_{\mathrm{sw}}$ (solar radiation modified by cloud losses), the evaporative heat flux $Q_{\mathrm{e}}$, and the combined longwave backradiation and sensible heat flux $Q_{\mathrm{lw}, s}$ are referred to here as the "net surface flux" or "air-sea flux." In addition, penetrative radiation through the base of the upper layer is included in this term. Heat flux due to vertical mixing $\left(Q_{\mathrm{m}}\right)$ has a small background component but is primarily associated with entrainment/detrainment evaluated in the Chen et al. (1994a) mixing scheme described above.

The heat flux formulation of Seager et al. (1988) was adopted to evaluate air-sea heat exchange, which requires only cloud cover and wind speed as atmospheric input. Seager et al. (1995) argued that specifying the air temperature (as has been required for some formulations of surface heat fluxes) implies that the atmosphere has an infinite heat capacity and is tantamount to specifying the SST. In Seager et al.'s (1988) formulation, shortwave heat fluxes are computed from solar harmonics reduced by a proportion of observed cloud (Reed 1977), and latent fluxes are found according to standard bulk formulas assuming that the humidity is a fixed proportion of the saturation humidity at the model SST. Longwave and sensible fluxes are evaluated using a simplified bulk formula that is proportional to the model SST. Harrison (1991) studied the sensitivity of model SST to variations of heat flux forcing and found that in the eastern Pacific, where the oceanic horizontal advection and upwelling were large terms in the heat balance, his GCM was relatively insensitive to inaccuracies in the specified atmospheric heat fluxes (about $1^{\circ}-2^{\circ} \mathrm{C}$ per $100 \mathrm{~W} \mathrm{~m}^{-2}$ ). This is reassuring, since in the present model we do not expect the simplified heat flux parameterizations to give accuracies better than about $20 \mathrm{~W} \mathrm{~m}^{-2}$ or more.

Wind forcing was the average annual cycle constructed from 30 yr (1961-90) of the Florida State University (FSU) wind product (Stricherz et al. 1992), with a constant drag coefficient of $1.3 \times 10^{-3}$. The FSU winds (on a $2^{\circ}$ by $5^{\circ}$ monthly grid) were bilinearly interpolated to the much-denser model spatial grid, then interpolated in time to the model 1-h timestep. Cloud fraction variations for the Seager et al. (1988) heat flux formulation was obtained from the 1982-94 average annual cycle 
of the ISCCP C2 satellite cloud product (Rossow and Schiffler 1991). This consists of monthly average fields based on visible and infrared images from operational weather satellites. The mean value of cloud fraction was empirically adjusted from the observed values to tune the model mean SST to agree with that of Levitus (1982). These adjustments were constant offsets of generally less than 0.1 cloud fraction, except very close to the coast of Mexico where the model SST otherwise becomes too warm, and the cloud fraction was adjusted upward by up to 0.3 .

All results shown here are for model year 10. Several test runs were made to examine the stability of the solution by comparing years $9-14$, and the 10th year was found to be typical of the average annual cycle. It is desirable to examine a single year rather than an average annual cycle, since, as we will show, eddy advection due to tropical instability waves (which would be averaged out in a composite annual cycle) are a key aspect of the balance. What is referred to as the "standard run" was forced with winds and clouds as above. In section 4 , we also discuss several runs made with modified forcing.

\section{b. Datasets used for comparison}

The principal ocean dataset used to compare with model output is the meridional line of TAO buoys along $110^{\circ} \mathrm{W}$ (Hayes et al. 1991b; McPhaden 1993). At $\pm 2^{\circ}$, $\pm 5^{\circ}$, and $\pm 8^{\circ}$ latitude, this line consists of thermistor chain moorings that measure temperature at 1-m depth and 10 subsurface depths down to $500 \mathrm{~m}$, as well as surface winds, relative humidity, and air temperature. Water temperatures are sampled six times per hour. At the equator, an enhanced mooring also measures zonal and meridional currents between the surface and 300 $\mathrm{m}$; these are a combination of mechanical current meters and downward-looking acoustic Doppler profilers. Kessler et al. (1996) discuss statistical and sampling error characteristics of the TAO buoy network.

We rely on the $110^{\circ} \mathrm{W}$ buoy line for subsurface temperatures and currents because it is in the center of the cold tongue region studied, and it has long time series with high temporal resolution. At the equator, observations have been made at $110^{\circ} \mathrm{W}$ since 1980 ; at the other latitudes (except $8^{\circ} \mathrm{N}$ ), the time series span at least $10 \mathrm{yr}$, so temporal aliasing is minimal. There are no other sources of observed subsurface current time series available in the east. Other sources of subsurface temperature information that might have been used include the volunteer observing ship (VOS) expendable bathythermograph (XBT) lines (Donoso et al. 1994) that also have long time series suitable for constructing annual cycles, but we chose to use the simultaneous current and temperature datasets that the TAO buoy network provides. Comparisons between model temperature fields and buoy time series along $125^{\circ}$ and $140^{\circ} \mathrm{W}$ were also undertaken, and the strengths and weaknesses of the model at those locations were found to be similar to those shown for $110^{\circ} \mathrm{W}$ in section 3 .

It was necessary to have regional coverage of SST to examine the patterns of evolution of this field in space and time. For this purpose we used the blended satellitein situ SST field produced at the National Centers for Environmental Prediction (Reynolds and Smith 1994). This is a weekly product on a $1^{\circ} \times 1^{\circ}$ grid that uses surface observations to reference satellite Advanced Very High Resolution Radiometer (AVHRR) radiometer measurements. Because the TAO buoys are one of the main surface references for the satellite SST in this region, the blended field agrees closely with the buoy time series at the buoy locations. In accordance with common usage, we will refer to this dataset as the "Reynolds SST."

\section{How well does the model simulate the observed annual cycle?}

In this section we evaluate the ability of the model to simulate the annual cycle in the eastern tropical $\mathrm{Pa}$ cific. This is not intended to be a complete validation of the model (see Chen et al. 1994a,b for other viewpoints) but constitutes the necessary verification of the simulation of the oceanic annual cycle in the eastern tropical Pacific region. The most important quantity for this purpose is, of course, SST, but we recognize that unless a solution represents the currents and vertical thermal structure reasonably well, agreement of model SST with observations may be fortuitous or the result of particular tuning. In that case, the model may be useless for diagnosing the processes of variability. In addition, we intend to improve the model physics and the fields used to force it, which requires understanding the importance of the advective terms and the mechanisms by which heat and momentum penetrate below the surface layer. Since future progress will undoubtedly call for coupled integrations, it is essential that weaknesses of the model be thoroughly understood in an ocean-only context so the difficult task of coupling can advance.

\section{a. SST}

The characteristic features of mean SST in the eastern tropical Pacific are the cold tongue along the Peru coast and extending west centered just south of the equator, separated by a sharp front from the warm band under the ITCZ (Fig. 1). Except near the coast, mean meridional gradients of SST are at least several times as large as zonal gradients. Mean winds are southerly or southeasterly everywhere south of the ITCZ, then poleward of this convergence zone they are northeasterly; in all regions the easterly component increases toward the west. Longshore winds off Peru and equatorial easterlies produce strong coastal and equatorial upwelling in nar- 

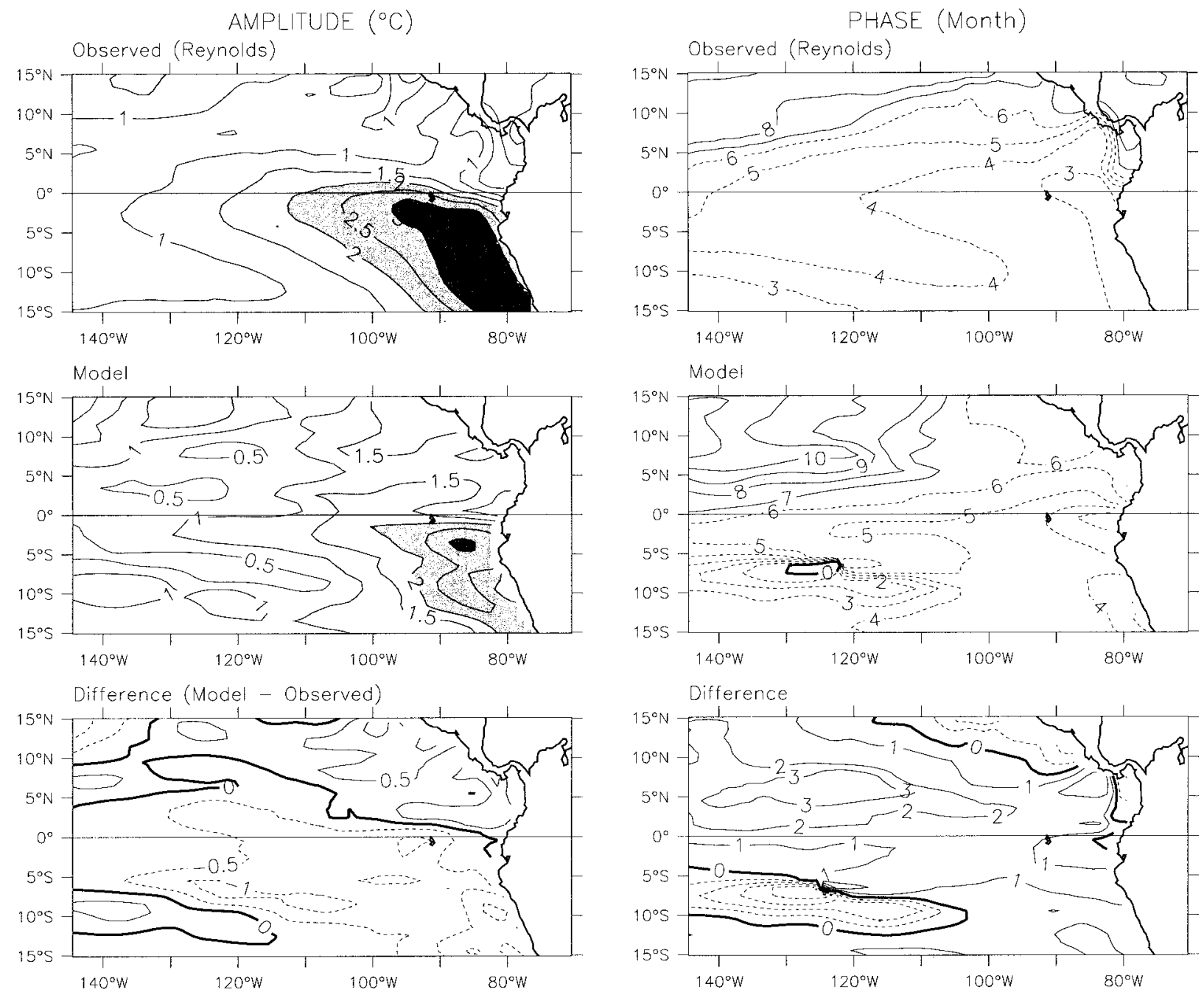

FIG. 2. Observed and modeled amplitude and phase of the 1 cycle $\mathrm{yr}^{-1}$ harmonic of SST. The observations are the Reynolds and Smith (1994) blended satellite product during 1984-93. Left panels show the amplitude $\left({ }^{\circ} \mathrm{C}\right.$, with shading for amplitude larger than $\left.1^{\circ} \mathrm{C}\right)$, and right panels show the phase (date of maximum SST, given as month numbers 1-12, where the contour labeled 1 is 1 January, the contour labeled 2 is 1 February, etc. Dashed contours are used for February-June, solid contours for July-December, and heavy line for January.). Top: observations; middle: model; bottom: difference (model minus observations).

row bands, with mean surface temperatures of $24^{\circ} \mathrm{C}$ or less (Fig. 1).

Chen et al. (1994b) showed that the model was able to simulate the basin-scale annual westward propagation of SST along the equator. Here we examine the situation in the eastern Pacific in somewhat more detail. Figure 2 shows the amplitude and phase of the 1 cycle $\mathrm{yr}^{-1}$ harmonic of SST in the model and in the Reynolds SST product for this region. The observed annual cycle amplitude (top left) is greatest (more than $2^{\circ} \mathrm{C}$ ) in the cold tongue region along the equator east of about $110^{\circ}$ and off the coast of Peru. [The second annual harmonic of SST is smaller than the first (usually several times smaller) everywhere in the region except inside the Gulf of Panama; the same is true of the wind stress components (Fig. 3).] A minimum of annual cycle amplitude (less than $1{ }^{\circ} \mathrm{C}$ ) of observed SST extends along the axis of the ITCZ and into the Southern Hemisphere in the west. The model SST amplitude (middle left) has a similar spatial pattern except for an unrealistic secondary maximum near the Central American coast and somewhat weaker variability off Peru (amplitude about $2.5^{\circ}-3^{\circ} \mathrm{C}$ where the observed amplitudes are about $1^{\circ} \mathrm{C}$ larger). The amplitude difference map (bottom left) shows these discrepancies clearly, with weaker model amplitude in the cold tongue region and stronger amplitude along the ITCZ and in the Gulf of Panama.

Phase of the 1 cycle $\mathrm{yr}^{-1}$ harmonic of SST (Fig. 2, right panels) is shown as the date of maximum SST. The annual cycle progresses northward and westward everywhere in the region; maximum SST appears in February-March south of $10^{\circ} \mathrm{S}$ and along the Peru coast, 


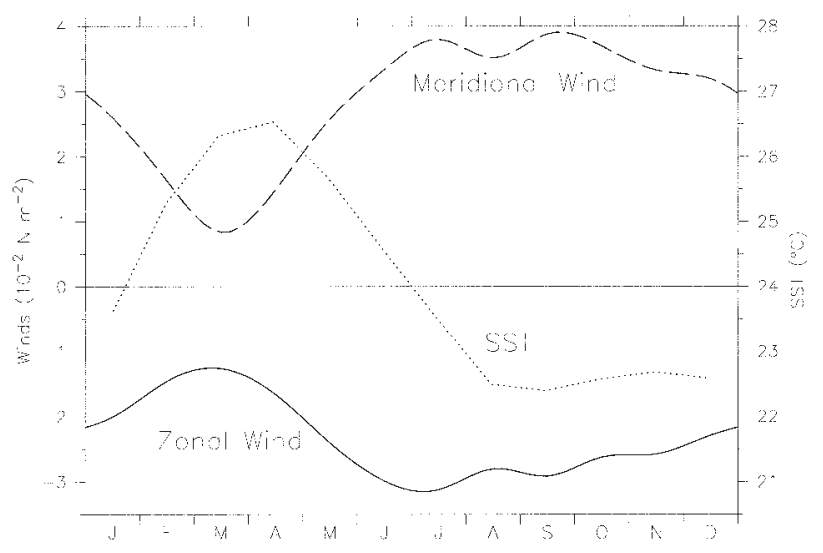

FIG. 3. Observed average annual cycle of zonal and meridional wind stress $\left(10^{-2} \mathrm{~N} \mathrm{~m}^{-2}\right.$, scale at left $)$ and SST $\left({ }^{\circ} \mathrm{C}\right.$, scale at right) at $0^{\circ}, 120^{\circ}-90^{\circ} \mathrm{W}$. The observations are the FSU wind product during 1961-90 and the Reynolds SST during 1984-93. Note the close phase relation of the two wind components, indicating very little change in direction during the year, and that the SST is warmest when the winds are weak.

while a September maximum is seen north of $10^{\circ} \mathrm{N}$, with a relatively sharp phase change (about 3 months in $3^{\circ}-$ $4^{\circ}$ latitude) along the ITCZ. The model spatial pattern of phase (middle right) is broadly similar but differs from the observed phase near about $6^{\circ} \mathrm{N}$ and $\mathrm{S}$ west of about $110^{\circ} \mathrm{W}$ [however, these are regions of very low amplitude in both model and observations (Fig. 2, left panels)]. The phase difference (right bottom) shows that over most of the region the model lags the observations by about $1-2$ months. The reason for this phase lag is unknown.

\section{b. Mixed layer depth}

Chen et al. (1994a,b) showed that variation of mixed layer depth (MLD) can be a decisive aspect of the tropical ocean heat and momentum balances. This is particularly true in the eastern Pacific where the thermocline is near the surface with consequent high stratification at shallow depths. The stability of the near-surface ocean in this region traps currents and fluxes in a thin layer, which makes the SST sensitive to relatively small influences. The amplitude of annual MLD variations can be half as large as the mean MLD itself, so proper accounting for these signals is crucial.

In the model, MLD is simply the thickness of the model upper layer, which deepens or shoals due to wind stirring and buoyancy flux from the atmosphere (KrausTurner physics) (see section 2a). No exactly comparable quantity can be computed from temperature observations, but a common standard is the depth at which the temperature is $0.5^{\circ} \mathrm{C}$ less than the SST (Hayes et al. 1991a). Experiments with other criteria as well as inspection of the long-time series of near-surface dailyaverage temperature from the TAO moorings along

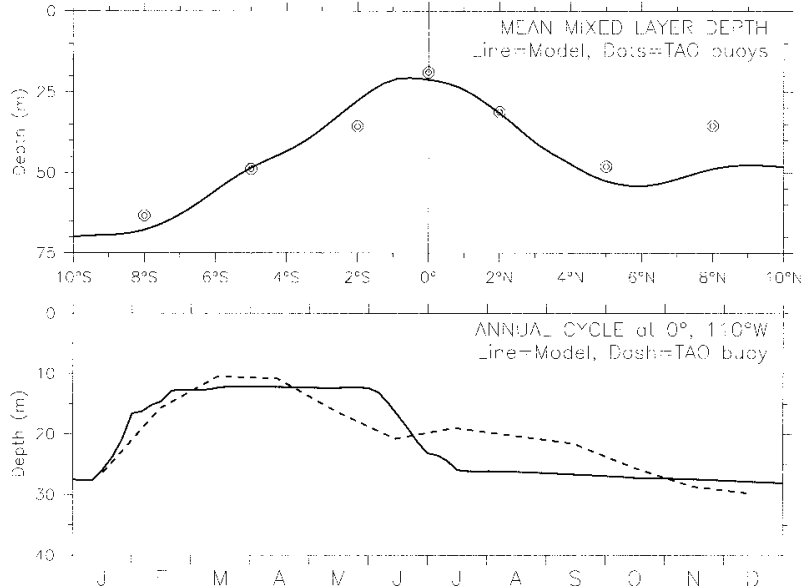

FIG. 4. Observed and modeled mixed layer depth (MLD). Observed MLD is found from the TAO moorings along $110^{\circ} \mathrm{W}$ and defined as the depth at which the temperature is $0.5^{\circ} \mathrm{C}$ less than the SST. Top: mean MLD along $110^{\circ} \mathrm{W}$. Solid line shows the model MLD (thickness of the model upper layer); large dots are observed mean MLD at each of the TAO moorings (at the equator, $\pm 2^{\circ}, \pm 5^{\circ}, \pm 8^{\prime}$ latitude). Bottom: MLD at $0^{\circ}, 110^{\circ} \mathrm{W}$ for an average annual cycle. Solid line shows the model; dashed line shows observed MLD averaged over 1980-95.

$110^{\circ} \mathrm{W}$ show that most of the time the daily profiles (though not the longer-term averages) display a sharp break at the top of the thermocline, so the exact temperature difference standard is not critical. Any difference standard from about $0.3^{\circ}$ to $1^{\circ} \mathrm{C}$ produces time series of MLD with very similar variability. It should also be noted that the vertical resolution of the buoys (usually every $20 \mathrm{~m}$ in the vertical) is not ideally suited to a precise determination of MLD, and the values we use were determined by vertical linear interpolation. However, at the equatorial mooring at $110^{\circ} \mathrm{W}$, an additional 10 -yr time series was made at $10 \mathrm{~m}$ depth, and almost $2 \mathrm{yr}$ of data were taken at $5 \mathrm{~m}$ depth. Examination of the better-resolved profile during this period did not suggest any modification of the conclusions reported here. Based on these results, in this paper "observed mixed layer depth" refers to the depth at which the temperature is $0.5^{\circ} \mathrm{C}$ less than the SST.

Figure 4 shows MLD from the model and TAO moorings along $110^{\circ} \mathrm{W}$. The top panel is the mean MLD over the record length at each mooring and over year 10 of the model standard run. The agreement is very good, with differences of $5 \mathrm{~m}$ or less everywhere except at $8^{\circ} \mathrm{N}$, where the model depicts MLD about $12 \mathrm{~m}$ deeper than observed (but the observed time series at this location is about half the length as the other moorings). The bottom panel shows the average annual cycle of the $16-\mathrm{yr}$ time series at the $0^{\circ}, 110^{\circ} \mathrm{W}$ TAO mooring and in the model. Both representations have minimum depths of about $12 \mathrm{~m}$ in March-April and maxima of about $27 \mathrm{~m}$ in December-January. In the model this annual shoaling in January-March is due primarily to 

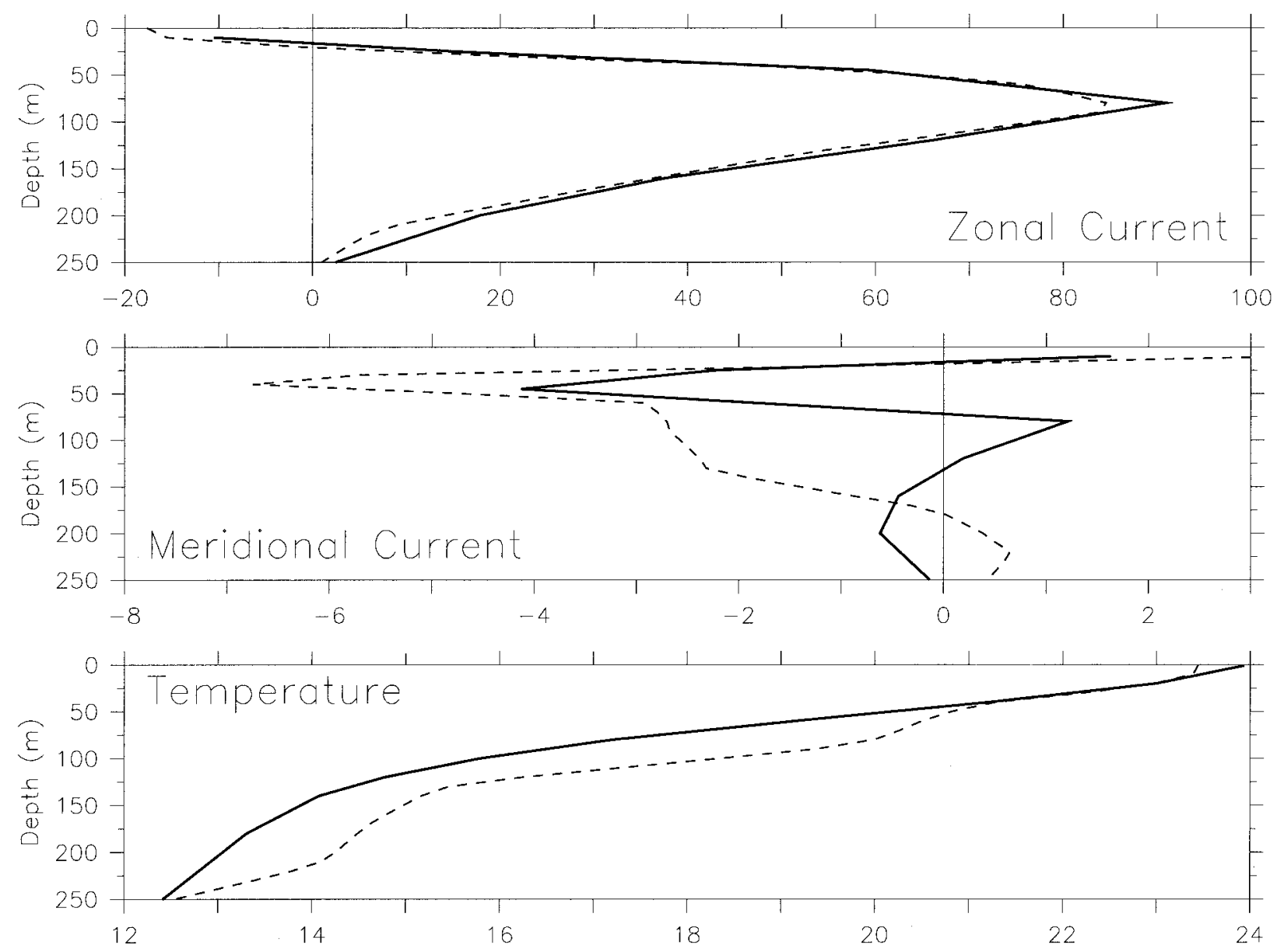

FIG. 5. Observed and modeled mean vertical profiles at $0^{\circ}, 110^{\circ} \mathrm{W}$. In each case, the solid line shows the TAO buoy observations (average over 1980-95), and the dashed line shows the model mean. Top: zonal current ( $\left.\mathrm{cm} \mathrm{s}^{-1}\right)$; middle: meridional current $\left(\mathrm{cm} \mathrm{s}^{-1}\right)$; bottom: temperature. No velocity observations were taken above 10-m depth.

the much smaller wind speeds at that time. Away from the equator, the MLD retains the same phase of annual variation with slightly larger amplitude. Although the model MLD differs in detail from the observed MLD, particularly in deepening rather abruptly in June-July when the winds strengthen, it represents the major features of the variability. Overall, this model simulates the major spatial and temporal features of MLD in the eastern tropical Pacific with acceptable realism.

\section{c. Vertical structure: Currents and thermocline depth}

\section{1) Average Quantities}

Figure 5 shows profiles of the mean zonal and meridional current and temperature from the TAO buoy at $0^{\circ}, 110^{\circ} \mathrm{W}$, and from the model. Modeled mean zonal current (top) is excellently represented throughout the upper ocean compared to observations. The westward South Equatorial Current (SEC) and eastward Equatorial Undercurrent are depicted at the correct depth and strength. Modeled mean meridional currents (middle) have the same character as observed in the upper $50 \mathrm{~m}$, with a cell consisting of northward flow in a thin surface layer and southward flow centered at 40-50 m. (Current meters were placed at $10,25,45$, and $80 \mathrm{~m}$ in this depth range so the vertical resolution is fairly crude.) In the model this cell is closed by upwelling centered south of the equator and downwelling to the north (see Fig. 6) and appears reasonably correctly modeled in the mean. Below about $50 \mathrm{~m}$, the model mean meridional currents bear little resemblance to those observed, although in both cases, the means are only about $1-2 \mathrm{~cm}$ $\mathrm{s}^{-1}$ in a regime with fluctuations of $\pm 50 \mathrm{~cm} \mathrm{~s}^{-1}$, so these deeper mean currents are probably not significantly different from zero in either model or observations. The strong near-surface shear of both current components suggests that vertical friction will be an important term in the model upper-layer momentum balances, and this turns out to be the case.

The simulated mean vertical profile of temperature at 


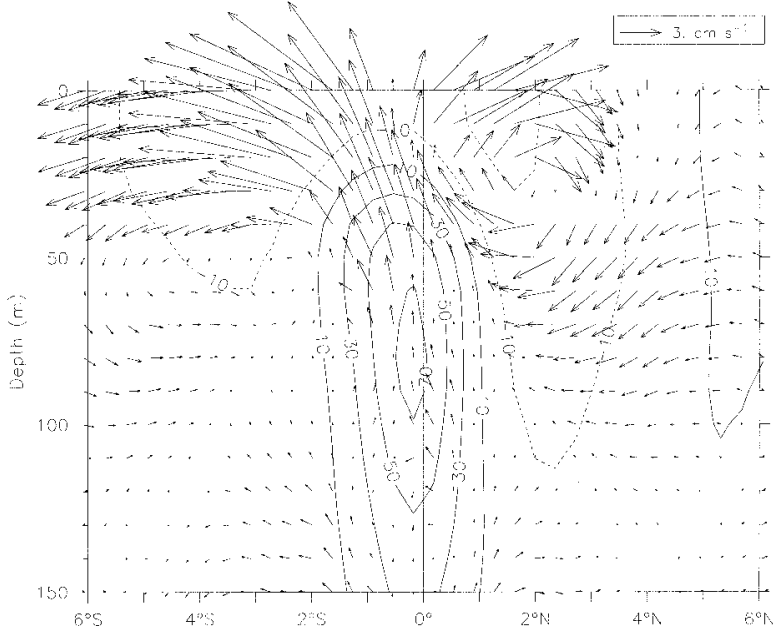

FIG. 6. Model mean meridional circulation in the eastern tropical Pacific (average over $120^{\circ}-90^{\circ} \mathrm{W}$ ). Vectors show the vertical-meridional flow. The vector key at upper-right scales the current speed, but the vector direction has been adjusted to correspond to the aspect ratio of the plot. Overlaid contours show the mean zonal curren (contour interval $20 \mathrm{~cm} \mathrm{~s}^{-1}$, solid contours show eastward current, dashed contours show westward current, and the zero contour is omitted)

$110^{\circ} \mathrm{W}$ (Fig. 5, bottom) shows a somewhat weaker thermocline than observed, and it is divided into three regions of sharp vertical gradient separated by unrealistic regions of weaker stratification. This discrepancy is a problem for the present analysis, since it implies that the modeled vertical advection of temperature (an important term in the balance, see section 4a) is probably too small. It is not known what causes this unrealistic vertical temperature gradient in the model.

Surface currents off the equator were checked using the TOGA drifting buoy climatologies (Niiler et al. 1998, manuscript submitted to J. Phys. Oceanogr.). The mean surface currents (Fig. 7) agree well with these observations; the principal difference in this region is that the drifters suggest a stronger flow joining the eastward North Equatorial Countercurrent (NECC) and the SEC near the Central American coast east of $85^{\circ} \mathrm{W}$. For the purposes of this study, which focuses on the SST west of $90^{\circ} \mathrm{W}$, the model simulation of near-surface currents and temperature in the east is probably adequate in the mean.

A final mean quantity that can be partially evaluated from observations is the vertical velocity. This cannot be measured directly, but indirect measurements of various types have agreed that mean vertical current speed is in the neighborhood of 1-3 $\mathrm{m} \mathrm{day}^{-1}$, with maximum upwelling just above the thermocline (Wyrtki 1981; Wyrtki and Eldin 1982; Bryden and Brady 1985; Halpern and Freitag 1987; Kessler and McPhaden 1995; Qiao and Weisberg 1996). Model mean $w$ (at the base of the mixed layer) is in good agreement with these results and is shown in Fig. 7, along with the model mean surface currents. Upwelling occurs at a speed of about $1 \mathrm{~m} \mathrm{day}^{-1}$ along the Peru coast and in the cold tongue, centered about $0.5^{\circ} \mathrm{S}$; the divergence of surface currents that produces equatorial upwelling is clear in

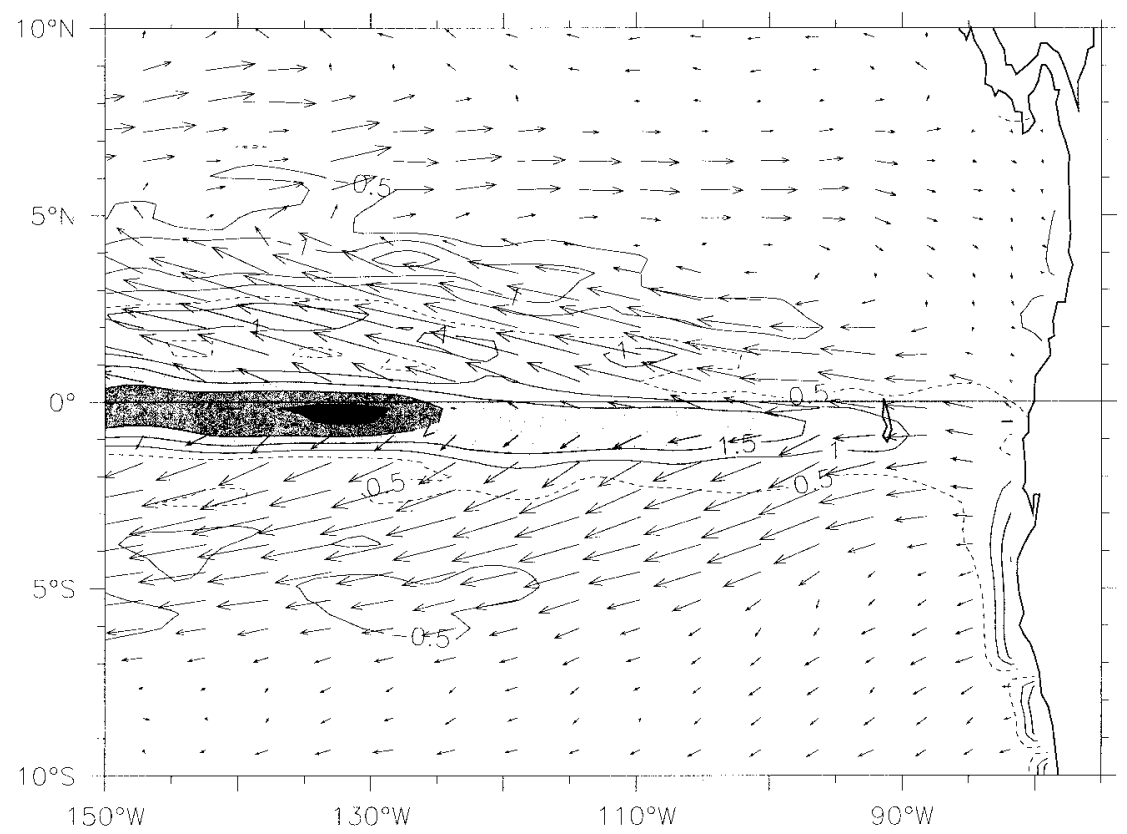

Fig. 7. Model mean vertical current ( $\mathrm{m} \mathrm{day}^{-1}$; contours and shading) and surface current vectors in the eastern tropical Pacific. The contour interval is $0.5 \mathrm{~m} \mathrm{day}^{-1}$; the zero contour is omitted and solid (dashed) contours indicate downwelling (upwelling). Shading indicates upwelling greater than $0.5 \mathrm{~m} \mathrm{day}^{-1}$. 

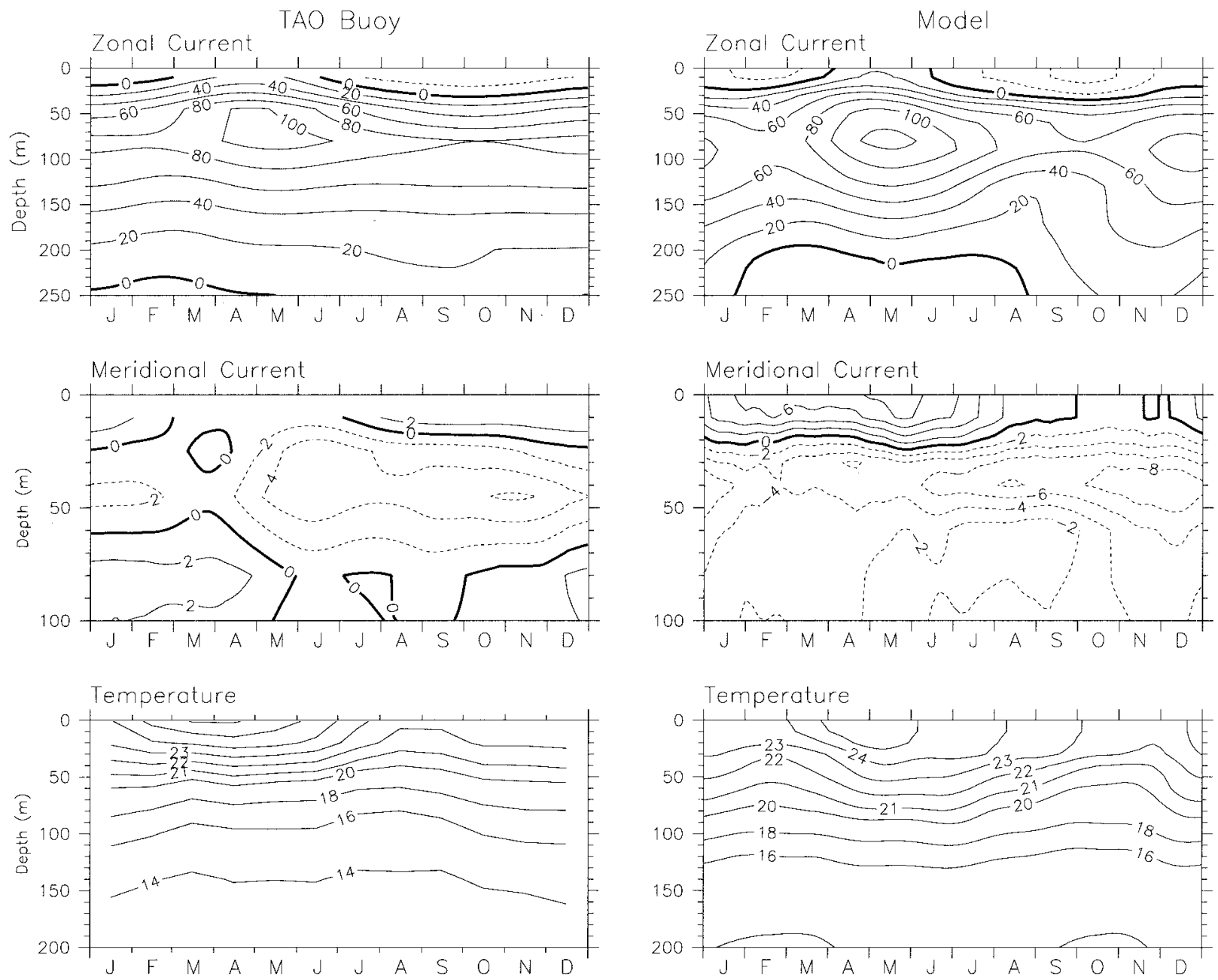

FIG. 8. Observed and modeled average annual cycles at $0^{\circ}, 110^{\circ} \mathrm{W}$. Left panels show the observations (TAO buoy, average over $1980-$ 95) and right panels show the model. Top: zonal current $\left(\mathrm{cm} \mathrm{s}^{-1}\right.$, contour interval $\left.20 \mathrm{~cm} \mathrm{~s}^{-1}\right)$; middle: meridional current $\left(\mathrm{cm} \mathrm{s}^{-1}\right.$, contour interval $\left.2 \mathrm{~cm} \mathrm{~s}^{-1}\right)$; bottom: temperature $\left({ }^{\circ} \mathrm{C}\right.$, contour interval $2^{\circ} \mathrm{C}$ below $20^{\circ} \mathrm{C}, 1^{\circ} \mathrm{C}$ above $\left.20^{\circ} \mathrm{C}\right)$. The depth range is different in each case. No velocity observations were taken above 10-m depth.

Fig. 7. Model upwelling transport is about $30 \mathrm{~Sv}$ in the eastern region $5^{\circ} \mathrm{S}-5^{\circ} \mathrm{N}, 120^{\circ} \mathrm{E}-90^{\circ} \mathrm{W}$, which is about one-fifth of the total (basinwide) equatorial upwelling in the model. The mean circulation in the meridional plane shows upwelling centered south of the equator, fed by a shallow return flow in the Northern Hemisphere (Fig. 6); about half the upwelling transport is due to the eastward weakening of the equatorial undercurrent and arises from the undercurrent core at depths of 50-75 m. Upwelling in the eastern Pacific is centered south of the equator because strong southerly winds force northward cross-equatorial currents that result in divergence south of the equator and convergence to its north (Philander and Delecluse 1983). In the central Pacific, where the meridional wind is much weaker, the meridional circulation pattern analogous to Fig. 6 is nearly symmetric about the equator; this symmetry can be seen at the west edge of Fig. 7.

\section{2) AnNual cycles}

Figure 8 compares the observed and modeled annual cycle of zonal and meridional current and temperature at $0^{\circ}, 110^{\circ} \mathrm{W}$. The observations are an average annual cycle from 1980 through 1995, while the model is the single year 10, smoothed to remove signals with periods shorter than about 50 days (the average of model years 9-14 is similar). The annual cycle of zonal current (top panels) is well represented at the surface, but at undercurrent level, the model simulation has too strong semiannual variability, with a second eastward peak in December. This feature is only barely apparent in the observations. The semiannual signal in the model is due to strong semiannual zonal wind forcing in the region near $180^{\circ}-150^{\circ} \mathrm{W}$, which propagates into the eastern $\mathrm{Pa}-$ cific as a Kelvin wave. Such variability is consistent with linear equatorial wave theory, and it is not known 



FIG. 9. Observed and modeled meridional current $\left(\mathrm{cm} \mathrm{s}^{-1}\right)$ at $0^{\circ}, 110^{\circ} \mathrm{W}$ during $1984-91$. The observations (solid line) are from the TAO buoy at 10-m depth (the year is labeled by each panel); the dashed line shows the model, which is year 10 repeated in each panel.

why the eastern Pacific in nature does not show this character of signal as strongly as expected from the observed forcing.

The annual cycle of meridional current (Fig. 8, middle panels) shows that the model smoothed surface current (with northward maximum in May) appears almost directly out of phase with the observed average annual cycle, which has a weak northward maximum in November-December. These low-frequency time series of meridional current are of great interest, since northward cross-equatorial flow in boreal spring is a key element of the Mitchell-Wallace hypothesis. The discrepancy between model and observations seen in Fig. 8 (middle) is thus a serious difficulty. The comparison at $110^{\circ} \mathrm{W}$ may be flawed, since the model meridional current field has a complex zonal structure with strong variations over even a few degrees longitude, even when smoothed as in Fig. 8. Model meridional currents at some nearby longitudes resemble the buoy times series more closely. Unfortunately, the TAO mooring at $110^{\circ} \mathrm{W}$ is the only location in the east where velocity time series are available, so we are unable to determine whether the model's short zonal scales of low-frequency meridional current are realistic. We also note that the smoothed signals in Fig. 8 have annual amplitudes about $2-4 \mathrm{~cm} \mathrm{~s}^{-1}$ and are dwarfed by the total variability that is about $15-20$ times greater. Figure 9 shows 8 yr of meridional current at $10-\mathrm{m}$ depth from the $0^{\circ}, 110^{\circ} \mathrm{W}$ TAO mooring and from the model. The observed time series are dailyaverage values, whereas the model values are snapshots every 2.5 days, with model year 10 repeatedly overlaid on each observed year. On the scale of Fig. 9, the average annual cycles shown in Fig. 8 would barely be visible.

In the following paragraph we discuss the tropical instability wave (TIW) variability (the roughly 20 -day period high-amplitude oscillations in Fig. 9), but here consider the April-June time period when Fig. 8 suggests the largest discrepancy between modeled and observed meridional current. At this time, the TIW are distinctly absent in both observations and model, and a lower-frequency signal is seen (Fig. 9). In both model and observations, the April-June period typically has one peak and one trough of meridional current; these 
have comparable amplitude to the higher-frequency TIW. The model year 10 April-June signal appears as a northward pulse of about $40 \mathrm{~cm} \mathrm{~s}^{-1}$; in the observations, a comparable northward pulse occurs in most of the years shown, but the timing of this flow varies over the April-June period. When an average annual cycle is constructed from many years of observations, these events average to near-zero (Fig. 8), but Fig. 9 shows that the average annual cycle is not a good representation of any individual year, nearly all of which contain a northward pulse similar to that in the model. Therefore, we conclude that although the observed average annual cycle of meridional current does not show a northward pulse during April-June, such a signal does in fact occur, but with variable timing, and the model representation is not as unrealistic as Fig. 8 suggests. In the model, the northward pulse is due to a transient imbalance between the meridional wind and the meridional pressure gradient. In the mean, and for most of the year, these two terms closely balance in the meridional momentum equation, and there is little acceleration of low-frequency meridional current. When winds increase in April-May (Fig. 3), the pressure gradient lags about a month behind, and the result is the northward pulse. Inspection of the 8-yr time series of observed wind corresponding to the meridional current shown in Fig. 9 does not show a simple or obvious relation between the annual date of the onset of southerlies and of the northward pulse, and the reason for the variable timing seen in Fig. 9 remains unknown.

The other important element of meridional current variability is the TIW. Numerous studies (e.g., Hansen and Paul 1984; Pullen et al. 1987; Halpern et al. 1988) have documented the characteristic occurrence of tropical instability waves in the months August-March, and their usual absence in boreal spring. The waves are particularly well observed in equatorial meridional current, although they can also be seen in excursions of the sharp SST front at $2^{\circ}-4^{\circ} \mathrm{N}$. TIW have been shown to produce a large flux of heat toward the equator (Hansen and Paul 1984; Bryden and Brady 1989) and must be taken into account to close the heat balance in this region (see section 4a2). The TIW are manifest in Fig. 9 as roughly 20-day period fluctuations with very large amplitude, as much as $1 \mathrm{~m} \mathrm{~s}^{-1}$ current change in 10 days, and they were usually but not always present throughout boreal fall-winter and absent during April-June of the years shown. The model (dotted line in Fig. 9) generates a vigorous TIW field, with frequency, amplitude, and seasonal modulation similar to those observed. Modeled TIW periods range from about 18 to 25 days; the model TIW amplitude is slightly smaller than that observed.

The annual cycles of temperature (Fig. 8, bottom panels) show roughly similar character of variability in both model and observations near the surface [although the model temperature cycle lags the observations by about a month (see section 3a)], but in the thermocline, a semiannual signal is quite evident in the model, as was noted above for zonal current. Also, the twice-a-year occurrence of weaker vertical gradient is seen to be unrealistic and contributes to the step-like mean gradient shown in Fig. 5 (bottom).

Overall, the annual cycles of subsurface currents and temperature produced by the model are less than satisfactory. The errors noted here are similar in nature and amplitude to those seen in other ocean GCMs in this region (D. E. Harrison 1996, personal communication). It is clear that further improvement of the ocean models and/or forcing fields is necessary before a fully successful simulation will be possible. However, the model simulation, while certainly not perfect, seems good enough to think that diagnosis of its annual SST balance may reveal aspects of the actual situation that cannot be identified from observations alone.

\section{Model experiments to study the SST balance}

As previous researchers (Enfield 1986; Chang 1994; Hayes et al. 1991a) have found, the surface layer heat balance in the eastern equatorial Pacific is not simple to describe or diagnose, since virtually every term in the balance is a significant contributor to the variability of the annual cycle. In addition, the effect of heating on SST is modulated by the changing depth of the mixed layer (e.g., Fig. 4). During model runs, seven terms of the SST equation are distinguished for each timestep and stored as output (see section 2a); for plotting simplicity we combine all the air-sea flux terms affecting the surface layer (shortwave, longwave, and penetrating radiation, and evaporation and sensible heat fluxes) into a single term labeled "net surface flux" [see (1)]. The solar declination cycle modified by changes in cloudiness provides the largest variability of this term. Where necessary, we differentiate among the constituents of net surface flux in the discussion.

It is also necessary to identify those contributions to the temperature terms that are due to low-frequency forcing, as opposed to the substantial influence of tropical instability wave eddy advection rectified into the annual cycle. We define low-frequency and eddy components of the advection as follows. Low-frequency SST advection is the product of smoothed current and smoothed SST gradient, for example, $\tilde{Q}_{u}=\tilde{u} \tilde{T}_{x}$ for the zonal component, where the tilde indicates a smoothed time series. Eddy SST advection is the difference between the total term $Q_{u}=u T_{x}$ and the low-frequency advection $\tilde{u} \tilde{T}_{x}$. The smoothing function chosen (a triangle) has half power at about the 75-day period. The results reported here are not especially sensitive to filter length as long as the filter separation is between TIW and semiannual frequencies. Following the division into two frequency bands, the eddy and total terms are then smoothed by the same filter for plotting (e.g., Fig. 10).

In each case, results are shown for the 10th year of each run. At the timescale at which the SST terms are shown in Fig. 11 (roughly 2-month filter), rms differ- 


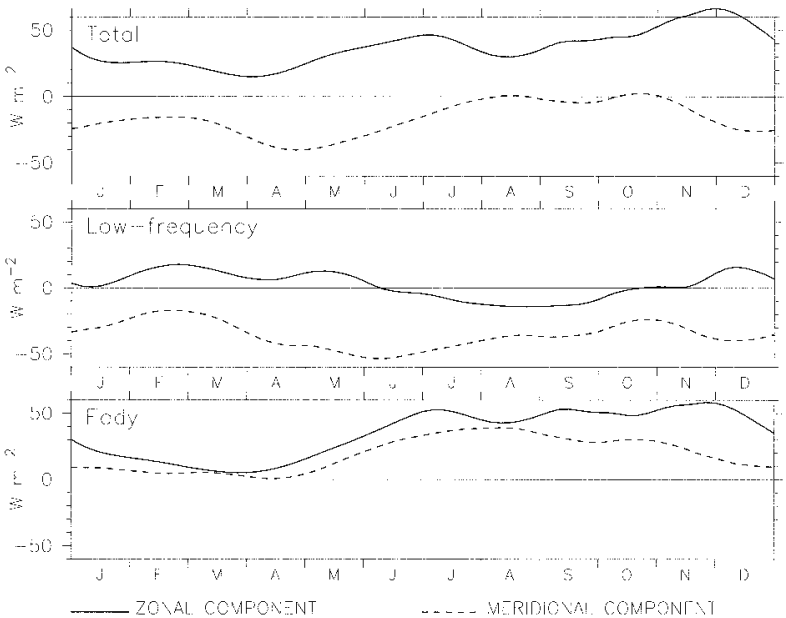

FIG. 10. Model eddy and low-frequency SST advection in the eastern equatorial Pacific (average over $2^{\circ} \mathrm{S}-2^{\circ} \mathrm{N}, 120^{\circ}-90^{\circ} \mathrm{W}$ ). In each case, the solid line shows zonal advection, the dashed line meridiona advection. Top panel: total advection; middle panel: low-frequency advection; bottom panel: eddy advection. See text for definitions. The total curves in the top panel are the same as in Fig. 11.

ences about the 6-yr (model years 9-14) average annual cycle were 7-8 $\mathrm{W} \mathrm{m}^{-2}$ for the three surface-layer advection terms and about $2 \mathrm{~W} \mathrm{~m}^{-2}$ for vertical mixing; these differences may be taken as a crude guide to the significance level of fluctuations of the temperature terms reported here.

\section{a. Influences on SST in the standard case}

The standard run was forced with full variation of winds and cloud fraction. Figure 11 shows the terms of the upper-layer SST balance (1) in the east Pacific cold tongue region for this run, smoothed to remove periods shorter than about 75 days. The heavy line shows the sum of all the tendency terms (equal to $\rho C_{p} h \partial T / \partial t$ ). Note that these smoothed terms (e.g., $\widetilde{u T}$ ) are not the same as the low-frequency terms $\left(\widetilde{u T}_{x}\right)$ defined above. The sign convention is that positive values indicate a warming tendency in the ocean. The annual range of $\rho C_{p} h \partial T / \partial t$ in the cold tongue is about $\pm 25 \mathrm{~W} \mathrm{~m}^{-2}$, and its annual cycle consists of warming during DecemberMarch, then cooling during July-September. Overall, warming roughly correlates with the peak of net surface (air-sea) flux and cooling with vertical advection, but maximum warming and cooling occur a month or more in advance of these terms, and so this is not the entire story. In addition, Fig. 11 shows that the variability of each of the terms at this timescale is at least as large as that of $\rho C_{p} h \partial T / \partial t$.

Figure 3 shows the annual cycle of wind stress components in the same region. Both components have similar annual cycles, with weak winds February-April and strong winds July-September. These monthly average winds in this region show little change in direction dur-

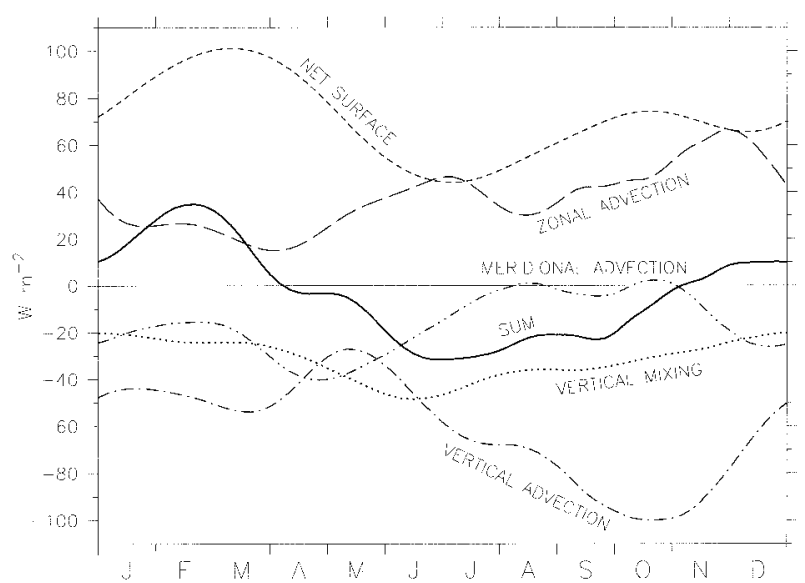

FIG. 11. Terms of the model upper-layer SST balance in the eastern equatorial Pacific (averaged over $2^{\circ} \mathrm{S}-2^{\circ} \mathrm{N}, 120^{\circ}-90^{\circ} \mathrm{W}$ ). Each term is labeled and corresponds to a term in (1). The thick solid line is the sum of all terms (equal to $\rho C_{p} h \partial T / \partial t$ ).

ing the climatological year (less than $20^{\circ}$ total range, always southeasterly) but large changes in speed (a factor of 2) during the year. This wind speed variation has profound effects on the SST annual cycle due to changes in evaporation, vertical mixing, upwelling, horizontal advection, and mixed layer depth. Upwelling is forced by zonal (and to a lesser extent meridional) winds; this produces eastward, southward, and cooling advective tendencies in the equatorial surface layer due to the mean vertical gradients of currents and temperature (Fig. $5)$.

\section{1) The AnNual Warming of EQUATORIAL SST}

During December-March, eastern equatorial SST warms, with all the temperature terms except horizontal advection contributing to the increase. The net surface flux rises about $30 \mathrm{~W} \mathrm{~m}^{-2}$ above its mean; this is due both to the passage of solar zenith and to reduced cloud cover during boreal spring (Fig. 12). Solar radiation at the top of the atmosphere increases by about $25 \mathrm{~W} \mathrm{~m}^{-2}$ during this time, and decreasing clouds add an additional roughly $35 \mathrm{~W} \mathrm{~m}^{-2}$ to the change (Fig. 12). However, the thinning mixed layer (Fig. 4, bottom) means that more of this radiation penetrates through the base of the layer, and this gives a loss of about $25 \mathrm{~W} \mathrm{~m}^{-2}$ compared to the thick mixed layer in December. (Note that since the shortwave radiation diminishes exponentially with depth, while its effect on SST varies inversely with mixed layer thickness, this loss of heat due to MLD thinning does not imply a reduction in SST.) The result is that net solar flux into the upper layer increases by about $35 \mathrm{~W} \mathrm{~m}^{-2}$ while the SST is warming. Weak wind speeds (Fig. 3) result in weaker evaporation during January-March. However, as SST warms, evaporation becomes more efficient, countering the weaker wind tendency in the bulk formula for latent heat loss, and the 
(a) Solar forcing in the obsence of clouds

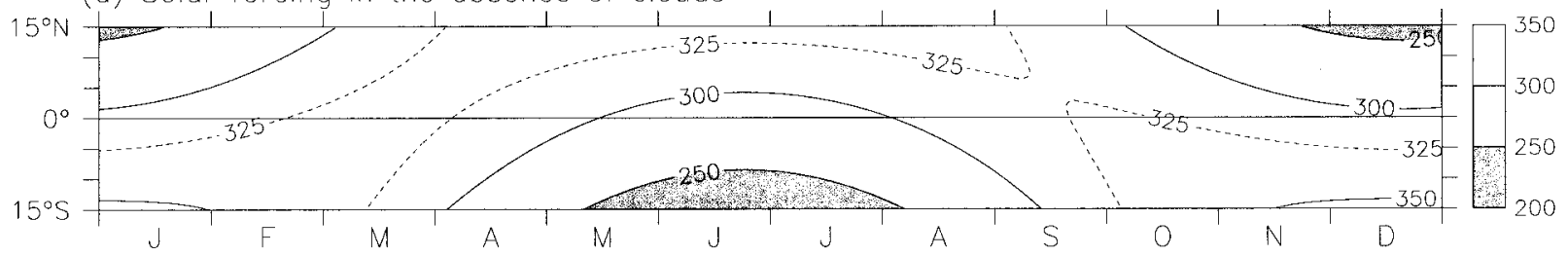

(b) ISCCP Cloud Fraction

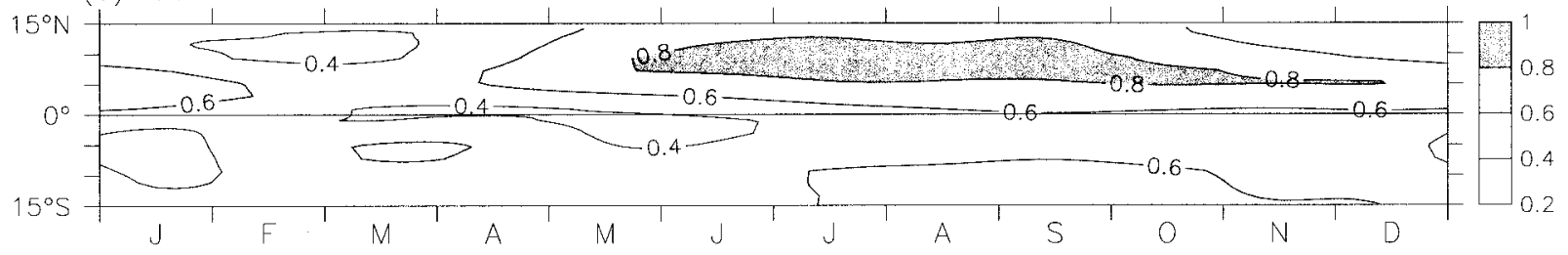

(c) Net solor forcing at the sea surfoce

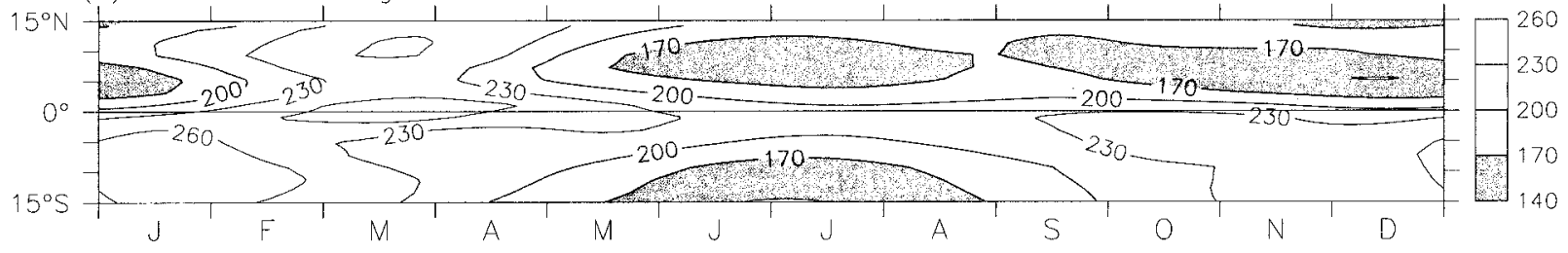

(d) Time series at the Equator

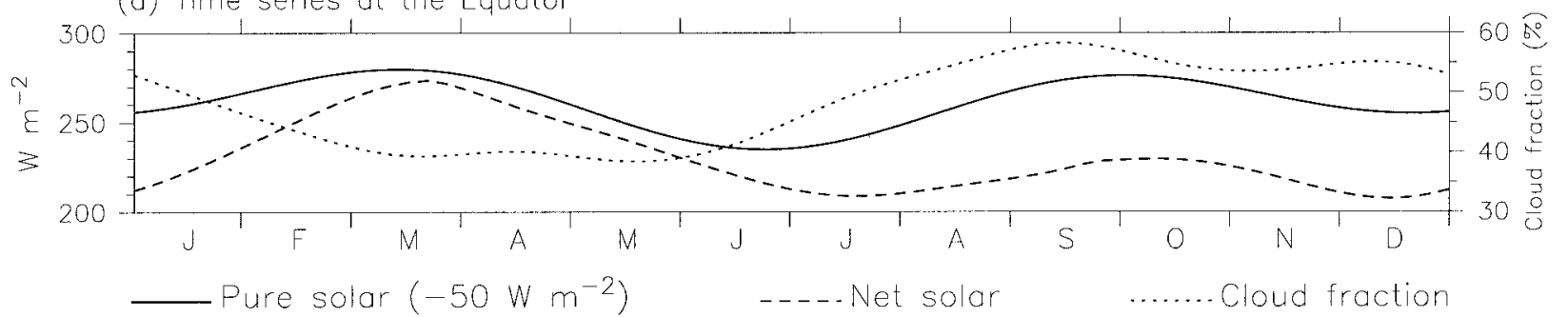

FIG. 12. Elements of the average annual cycle shortwave forcing terms that drive the model. (a) Solar radiation in the absence of clouds $\left(\mathrm{W} \mathrm{m}^{-2}\right)$. The contour interval is $50 \mathrm{~W} \mathrm{~m}^{-2}$, with a supplemental contour at $325 \mathrm{~W} \mathrm{~m}^{-2}$. Shading indicates radiation less than $300 \mathrm{~W} \mathrm{~m}{ }^{-2}$. (b) Cloud fraction from the ISCCP C2 dataset, averaged over 1984-93. The contour interval is 0.2 . Shading indicates cloud fraction greater than 0.4. (c) Net shortwave radiation received at the sea surface $\left(\mathrm{W} \mathrm{m}^{-2}\right)$, after taking into account losses due to albedo and cloud cover, according to the Reed (1977) formula. The contour interval is $30 \mathrm{~W} \mathrm{~m}^{-2}$, and shading indicates net radiation less than $230 \mathrm{~W} \mathrm{~m}^{-2}$. (d) Time series at the equator of the quantities in panels a-c. The scale for shortwave radiation is at left and for cloud fraction at right. The legend lines below the panel identify the curves.

net change of latent heat flux during this period is small, about 5-8 $\mathrm{W} \mathrm{m}^{-2}$ of (anomalous) warming compared to November. Figure 11 combines all these terms as the net surface flux, which amounts to a total contribution of about $30 \mathrm{~W} \mathrm{~m}^{-2}$ to the SST warming in boreal winterspring.

In the ocean, weak winds also augment warming by reducing vertical mixing; during December-March, vertical mixing is minimum, and this term represents an anomalous warming of about $10 \mathrm{~W} \mathrm{~m}^{-2}$ (Fig. 11). Weak zonal winds result in reduced upwelling, and Fig. 13 shows that upwelling during February-April occurs at less than half the speed seen in the strong trade wind part of the year, and the region of strong upwelling is smaller. Reduced upwelling should be an anomalous (advective) warming tendency, but this is partly opposed by strengthening of the vertical temperature gradient (Fig. 8); as a result, vertical advection contributes a relatively small anomalous warming of about $20 \mathrm{~W} \mathrm{~m}^{-2}$ (Fig. 11).

Both horizontal advection terms represent relatively weak anomalous cooling tendencies during the December-March warming, averaged over the region $2^{\circ} \mathrm{S}$ to $2^{\circ} \mathrm{N}$ (Fig. 11). However, it is important to distinguish between the low-frequency tendencies due to smooth wind forcing fields and the tendencies due to TIW advection, which are at least as large. At low frequencies, the zonal gradients of SST are weak (Fig. 1), and even with the springtime reversal of surface current (Fig. 8), low-frequency SST variations due to zonal currents are small compared to other terms (Fig. 10, middle). On the other hand, the large meridional SST gradient means 


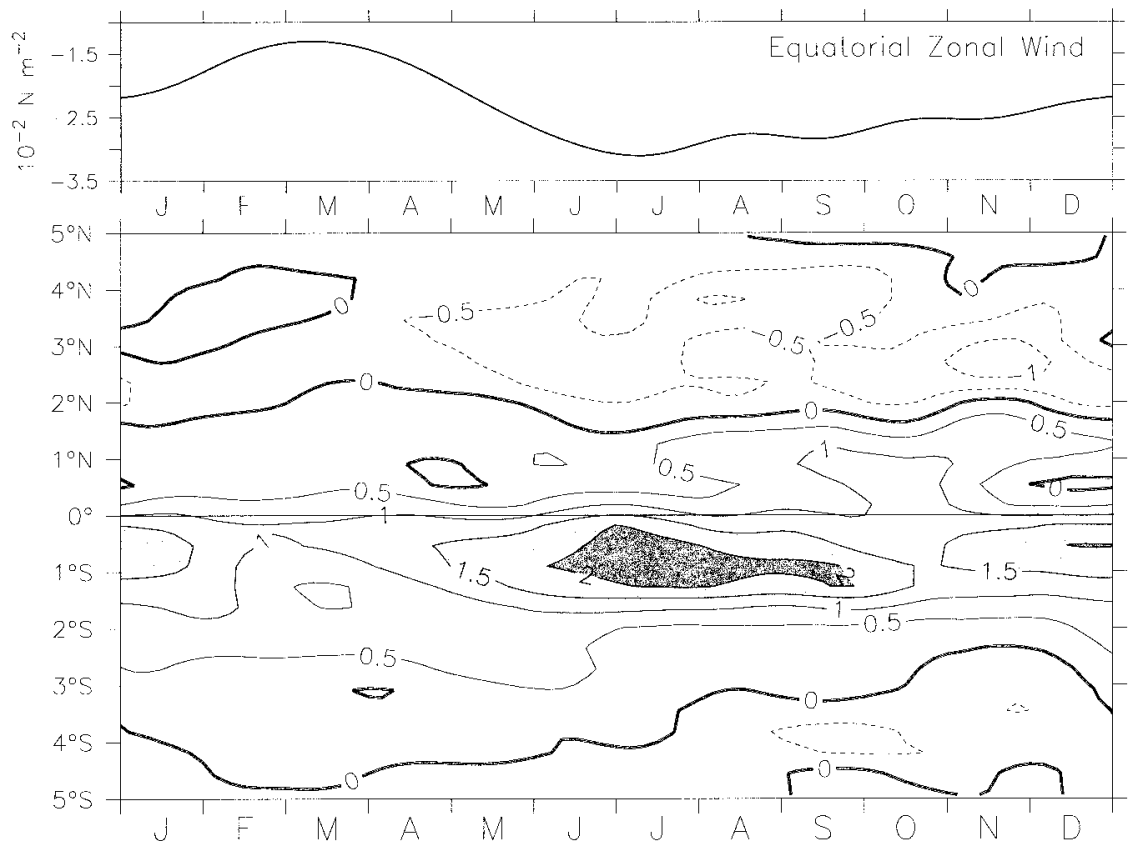

FIG. 13. Model average annual cycle of vertical velocity $\left(\mathrm{m} \mathrm{day}^{-1}\right)$ at the base of the upper layer in the eastern tropical Pacific (main panel). The contour interval is $0.5 \mathrm{~m} \mathrm{day}^{-1}$, and shading indicates speeds greater than $0.5 \mathrm{~m}^{d_{a y}{ }^{-1}}$ (of either sign). The small top panel shows the corresponding observed (FSU) equatorial zonal wind.

that cross-equatorial wind-driven currents can produce large low-frequency changes in SST, as suggested by Mitchell and Wallace. Low-frequency meridional advection will be seen to be an important term a few months later in the year, but during the DecemberMarch warming phase it makes a relatively small contribution (Fig. 10, middle).

Horizontal eddy temperature advection (due essentially to TIW in this region) is a warming term all year within $2^{\circ} \mathrm{S}$ to $2^{\circ} \mathrm{N}$, representing a tendency of $15-80 \mathrm{~W}$ $\mathrm{m}^{-2}$ (about $0.5^{\circ}-2^{\circ} \mathrm{C}$ month $^{-1}$ ) (Fig. 10, bottom). Both zonal and meridional eddy advection components are small (anomalously cooling) during December-May, even though the energetic waves continue through March, since there are smaller background temperature gradients in the region at that time. Therefore, variability of TIW eddy advection opposes the December-March warming.

In sum, the warm SST peak in boreal spring is due to a complicated mix of factors that would be very difficult to simulate accurately in a simpler model. Many of the important terms are those that would be represented in a one-dimensional model forced by local clouds and winds (i.e., the radiative fluxes, evaporation, and vertical mixing). However, variations in upwelling and eddy advection are significant influences on the total signal. These depend on changing spatial gradients of the surface temperature and currents and could not be modeled one dimensionally.
2) The annual cooling of equatorial SST (ONSET OF THE COLD TONGUE)

During June-October, SST cools in the eastern equatorial Pacific, and the cold tongue expands westward. As in the case of the annual warming, the principal terms driving the model simulation at this time appear to be the net surface fluxes and vertical advection, while both horizontal advection terms represent anomalous warming through most of the cooling period (Fig. 11). However, as for the warming period, this simple picture masks strong differences between low-frequency and eddy advection, as well as a complex mixture of influences including solar zenith position, cloud fraction, mixed layer depth, and evaporation.

Solar shortwave forcing on the equator, absent clouds, is principally semiannual, with equinoctial maxima about $45 \mathrm{~W} \mathrm{~m}^{-2}$ higher than the solstice values (Fig. $12 \mathrm{~d})$. However, cloud fraction in this region is least in March and increases during June-September. The convolution of this 1 cycle $\mathrm{yr}^{-1}$ cloud signal with the mainly semiannual solar variation produces a relatively higher shortwave peak in March and a much smaller September peak, about $45 \mathrm{~W} \mathrm{~m}^{-2}$ lower than the March value. Cloud variations also delay the surface signature of the June solar minimum by about 1 month. The effect of cloudiness means that the net shortwave flux at the sea surface is dominated by the 1 cycle $\mathrm{yr}^{-1}$ harmonic. On the other hand, the deeper mixed layer depth in the last half of the year (Fig. 4) counters the cloud variability 
impact on heat flux, since less of the solar radiation penetrates through the MLD base, and this reduces the effective March-September flux decrease into the upper layer by about half. Increasing wind speed in May-June at first increases evaporative heat loss by about $20 \mathrm{~W}$ $\mathrm{m}^{-2}$ over its March value; then as the SST cools the still-strong wind becomes a less-efficient evaporator, and this term reduces in magnitude. The net effect of these air-sea fluxes on the upper layer is that net surface flux drops rapidly by about $55 \mathrm{~W} \mathrm{~m}^{-2}$ from March to June, then increases by less than $30 \mathrm{~W} \mathrm{~m}^{-2}$ to the second (lower) warm peak in September (Fig. 11). The net surface flux is thus an anomalous cooling term during most of May-December, and this change is a major contribution to cold tongue onset, particularly during the initial stages in May and June. Of course, the cloud variations are not independent of SST, so complete understanding of the net solar flux effect on SST will require a coupled analysis.

As southeasterly winds accelerate in April-May (Fig. 3 ), upwelling increases, as do westward and northward currents (Figs. 8 and 13). (We note that these horizontal velocity tendencies are the opposite of those due to vertical advection, since upwelling gives eastward and southward tendencies at the surface. In fact, the model horizontal momentum terms suggest that in the surface layer, at timescales longer than 1 month, the principal balance is a linear one among wind stress, the pressure gradient, and vertical friction.) Although the surface current is increasingly westward after April, zonal advection remains a relatively small contributor to the cooling. It is tempting to think of the equatorial cold tongue expanding westward from the Peru coastal upwelling region (e.g., Fig. 2). However, at low frequencies, the zonal SST gradient is never large west of $90^{\circ} \mathrm{W}$, and zonal advection is not a major part of the equatorial cooling in this model (Fig. 10). [Zonal advection is a significant factor well south of the equator, however; see section $4 \mathrm{a}(3)$.] On the other hand, meridional advection is a large low-frequency cooling term at this time in the equatorial region. The April-May northward current that produces the cooling is the pulse discussed in section 3c(2) (Fig. 9). This appears to be the process suggested by Mitchell and Wallace. It produces a cooling anomaly of more than $0.75^{\circ} \mathrm{C}$ month $^{-1}$, equivalent to about $30 \mathrm{~W} \mathrm{~m}^{-2}$ (Fig. 11 and Fig. 10, middle). The combination of meridional advection and cooling due to decreased net flux from the atmosphere (which is twice as large a signal) begins the annual onset of the cold tongue (Fig. 11). However, after about 2 months, northward flow decreases as the meridional pressure gradient builds up to balance the southerly winds. For the rest of the year, although strong southerlies continue, the low-frequency meridional current is small (Fig. 8), and the SST advection it induces is a relatively weak signal (Fig. 10).

Intensifying zonal winds in April-May rapidly produce a doubling of equatorial upwelling speed (Fig. 13), and for the remainder of the year, this term encourages cooling of the cold tongue, with negative values as strong as $100 \mathrm{~W} \mathrm{~m}^{-2}$ (Fig. 11). All the other terms are tending toward positive values at this time, so the continued strong equatorial cooling is clearly due to upwelling.

The second half of the year is the period of strongest TIW (Fig. 9), and these produce the major contribution to horizontal advection at this time. Figure 14 shows SST and surface currents on a typical day during the active TIW season. The SST front is distorted with intrusions of warm water southward to the equator and cold water northward to about $5^{\circ} \mathrm{N}$. On this model day, instantaneous SST advection was as large as $0.2^{\circ} \mathrm{C}$ day $^{-1}$, particularly warming on and just north of the equator. Note that during equatorial northward surges (at $121^{\circ}$ and $112^{\circ} \mathrm{W}$ in Fig. 14), the minimum SST (hence zero meridional gradient) occurs at the equator, so these northward flows do not produce large advective cooling there. In addition, much of the northward flow is along isotherms. TIW zonal advection on the flanks of the intrusions is as large a warming term as meridional advection, in contrast to the mean state where there are only small zonal gradients of SST. Over the subsequent month, both warm and cold wave "crests," shown in Fig. 14, pinch off and leave regions between $1^{\circ}$ and $4^{\circ} \mathrm{N}$ with mostly homogenized water at about $25^{\circ} \mathrm{C}$. Averaged over $2^{\circ} \mathrm{S}-2^{\circ} \mathrm{N}$ and $120^{\circ}-90^{\circ} \mathrm{W}$, both horizontal eddy components are similar in magnitude, representing warming of about $1^{\circ} \mathrm{C}$ month $^{-1}$ (roughly 40 to $60 \mathrm{~W} \mathrm{~m}^{-2}$ ) from June to December (Fig. 10), and therefore the TIW produces a significant moderation of the annual cooling due to upwelling. This conclusion agrees qualitatively with that of Hansen and Paul (1984); however, the values of heat flux they estimated were almost twice as large as those seen in our model, averaged over $2^{\circ} \mathrm{S}-2^{\circ} \mathrm{N}$. The corresponding eddy cooling on the northern side of the TIW region at $3^{\circ}-5^{\circ} \mathrm{N}$ is only about one-fifth as large as the equatorial eddy heating, as suggested by the weaker currents in that region in Fig. 14.

\section{3) The off-equatorial annual cycle of SST IN THE STANDARD RUN}

All the oceanic SST terms decrease in amplitude away from the equator to less than half their equatorial maxima by $2^{\circ} \mathrm{N}$ and $2^{\circ} \mathrm{S}$, especially the vertical exchange terms. With a few exceptions, annual variation of all the ocean terms becomes much less important than the surface flux in the SST equation poleward of $4^{\circ} \mathrm{N}$ and $4^{\circ} \mathrm{S}$. Exceptions include zonal advection, which cools the SST at $2^{\circ}-12^{\circ} \mathrm{S}$, where the SEC and Ekman wind drift advects cold water west and south from the cold pool, most strongly during the second half of the year. During this period, the westward current is strongest, the zonal temperature gradient in the region is also larger than earlier in the year, and cooling associated with zonal 


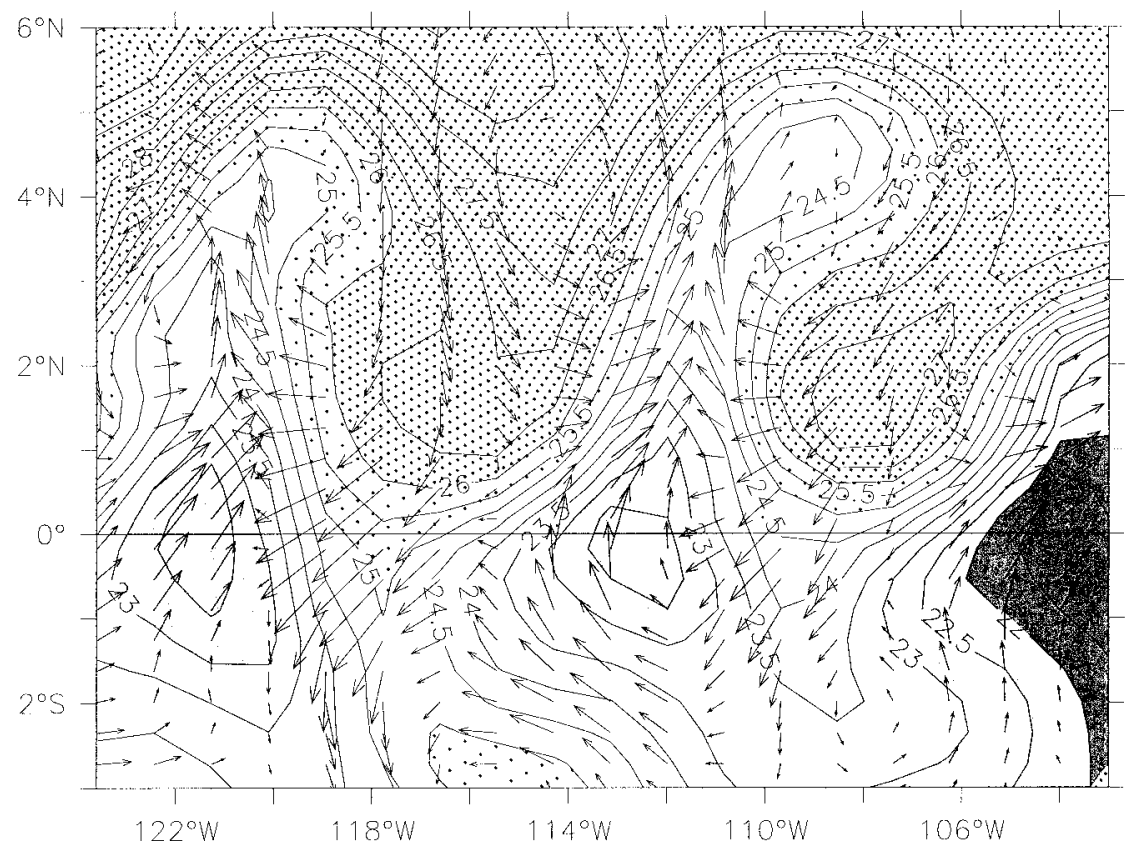

FIG. 14. An example of the model tropical instability wave field. Contours show SST, with a contour interval of $0.5^{\circ} \mathrm{C}$. Shading indicates SST less than $24^{\circ} \mathrm{C}$, and dot-hatching indicates SST greater than $25^{\circ} \mathrm{C}$. Vectors show the eddy velocity field (see text for definition).

advection increases by about $40 \mathrm{~W} \mathrm{~m}^{-2}$ near $4^{\circ}-5^{\circ} \mathrm{S}$ (about $20 \mathrm{~W} \mathrm{~m}^{-2}$ near $10^{\circ} \mathrm{S}$ ). Also, meridional advection associated with the May-June northward pulse discussed above is a significant cooling effect (about 20$25 \mathrm{~W} \mathrm{~m}^{-2}$ ) as far as $4^{\circ} \mathrm{N}$ but is weak otherwise. Of course, changes in the ocean also have an indirect influence on the air-sea flux terms through changes in mixed layer depth (but MLD variance also lessens away from the equator). Despite these exceptions, Fig. 15 shows that the air-sea fluxes define the overall character of annual SST variability throughout the off-equatorial region, and the ocean terms are relatively small. The air-sea flux signals shown in Fig. 15 (top) are mostly the result of solar position (the heavy line in the figure is the solar declination) modulated by clouds (Fig. 12). During December-April, cloudiness is at its minimum over $15^{\circ} \mathrm{S}-15^{\circ} \mathrm{N}$ (Fig. 12b), and the heating maximum is nearly coincident with the solar declination. The second expected annual solar maximum in September is obscured by heavy cloud cover between the equator and about $15^{\circ} \mathrm{N}$ (Fig. 12b); these are deep convective clouds in the ITCZ. In the Southern Hemisphere, variations of cloudiness are less pronounced, and the heating pattern in Fig. 15 is primarily due to the cycle of solar declination. It is worth noting that the warming band seen in Fig. 15 (middle) stretching from about $2^{\circ} \mathrm{S}$ in February to $10^{\circ} \mathrm{S}$ in August (and the weaker corresponding band in the Northern Hemisphere) is due to a Rossby wave reflected from the South American coast in the model. This wave reflection has not been observed and probably is exaggerated in the simulation (as such reflections often are in tropical ocean models).

\section{b. Modified forcing experiments}

In addition to the standard run, three experiments were performed to isolate and evaluate the influences on the ocean of the cloud variations and the two components of the wind. The experiments were conducted simply by setting each of these forcing functions in turn to equal its time mean value at each location. In the adjusted wind experiments, only the dynamical effect of the winds were altered, with no change in the wind speed. This means that in these runs no change was made to the latent heat fluxes or to mixing due to wind stirring, which can be crucial aspects of the wind forcing (Chang 1994). This choice was made in order to isolate the dynamical effect of the winds on processes like upwelling and advection, without the complications of thermodynamic effects.

The standard case is not equal to the average of the three partial simulations, since the dynamics and thermodynamics are somewhat nonlinear; however, the difference between a partial solution and the standard case is taken as an index of how important that forcing element is to the variation of a particular quantity. For example, if setting the meridional wind to its mean resulted in a significant change in some aspect of the SST field, but the fixed-forcing experiments for zonal wind and cloud fraction produced little modification to this 


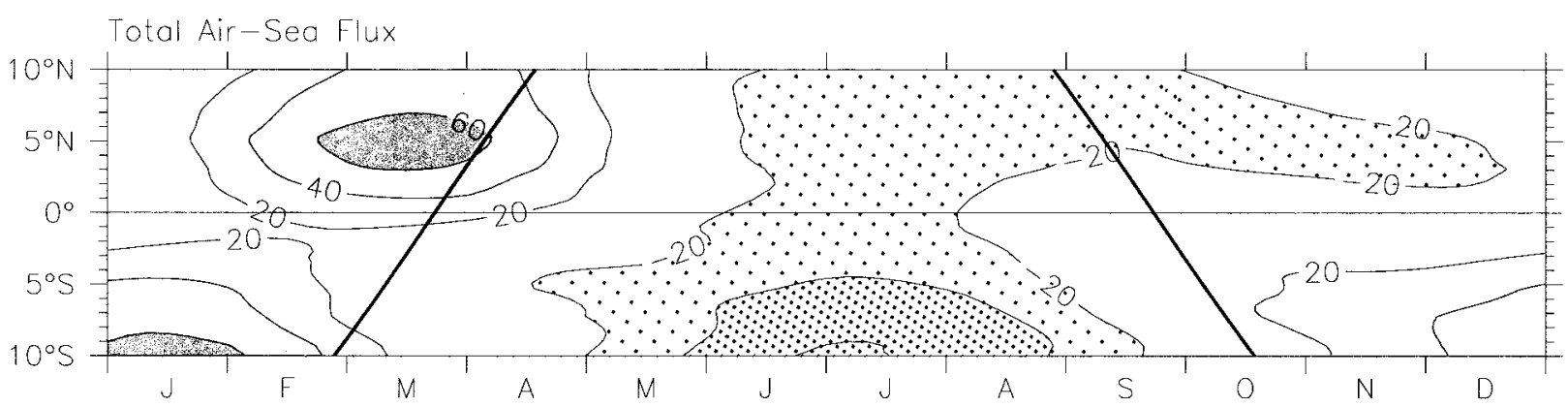

Ocean Advection + Vertical Mixing

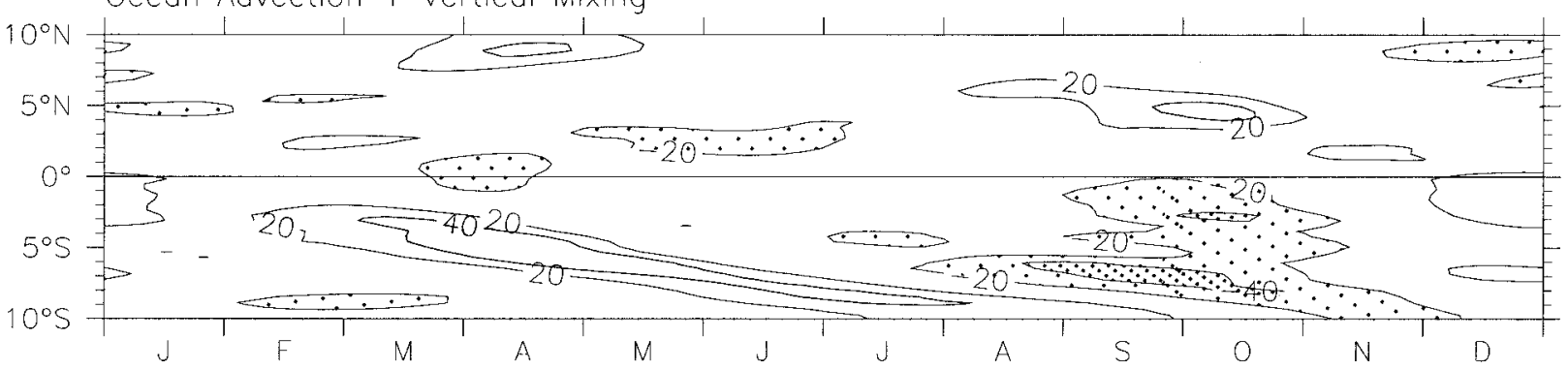

Sum of all terms $=\rho \mathrm{C}_{p} h \mathrm{dT} / \mathrm{dt}$

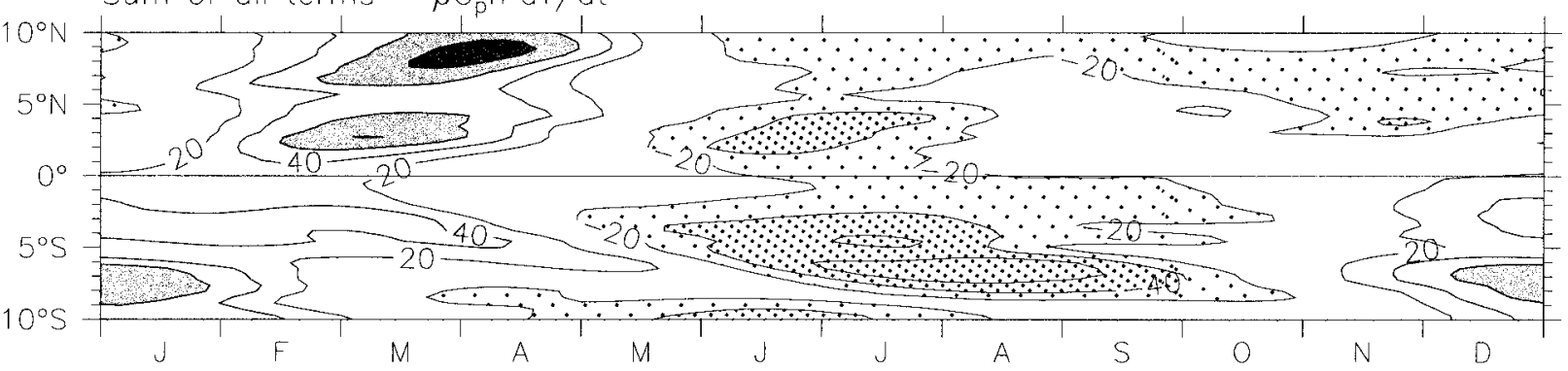

FIG. 15. Terms of the model average annual cycle SST balance $\left(\mathrm{W} \mathrm{m}^{-2}\right)$ in the eastern tropical Pacific. In each case, the contour interval is $20 \mathrm{~W} \mathrm{~m}^{-2}$ (no zero contour). Shading shows positive (warming the ocean) terms and dot-hatching shows negative terms. Top: Combined air-sea flux (net solar + evaporation + longwave and sensible heating). Middle: Combined ocean terms (advection + vertical mixing). Bottom: Sum of all terms (equal to $\rho C_{p} h \partial T / \partial t$ ).

aspect of the solution, then this was taken as evidence for the importance of forcing by the meridional wind variations in that region. In many comparisons, two of the partial solutions were found to be similar to the standard case, and only one differed greatly from the others; in those cases it was relatively easy to distinguish the specific forcing element responsible for aspects of the SST variations. In other comparisons, it was possible to identify important forcing elements at particular times of the year. Several other experiments were performed by modifying other aspects of the forcing, including setting the wind components or cloud fraction to zero, changing the solar cycle, and modifying the wind speed, but the three experiments cited demonstrate the main conclusions, and in the interest of simplicity, these are the only ones reported here in detail.

The adjusted-forcing experiments were the following.

1) Fixed meridional wind: The meridional wind component was set to its mean value at each location.
Zonal wind, cloudiness, solar forcing, and all other model parameters were as the standard case.

2) Fixed zonal wind: As in 1) but with fixed zonal wind (meridional wind was as in the standard case).

3) Fixed cloud fraction: The cloud fraction was set to its mean value at each location. Wind forcing was as in the standard case.

Figure 16 compares SST in the regions near the equator for the standard run and the three altered-forcing runs.

\section{1) FIXED MERIDIONAL WINDS}

In general, SST differences between the standard run and the run with fixed meridional winds in the eastern tropical Pacific were found to be smaller than in either of the other altered forcing experiments. Overall, the annual amplitude of SST in this altered forcing run is similar to that of the standard run (Fig. 2), with the 

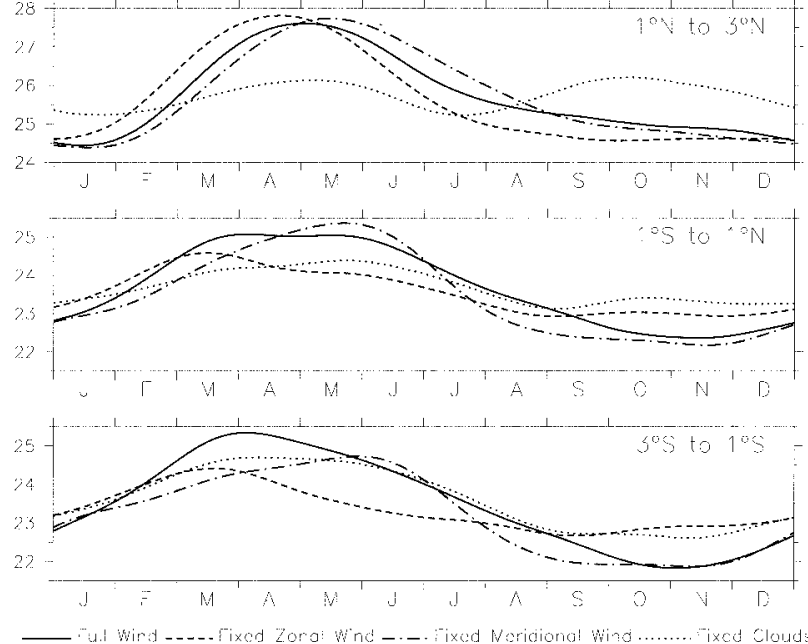

FIG. 16. Comparison of the average annual cycle of model SST for the standard run and the three altered forcing experiments in the eastern tropical Pacific. Top: $1^{\circ}-3^{\circ} \mathrm{N}$; middle: $1^{\circ} \mathrm{N}-1^{\circ} \mathrm{S}$; bottom: $3^{\circ}-$ $1^{\circ} \mathrm{S}$. The legend lines below the bottom panel identify the curves.

exception of the near-coastal region off Peru, where the amplitude is reduced by about a factor of 2 (since fixing the meridional wind greatly reduces the variation of Peru coastal upwelling).

Away from the coast, the largest change in the fixed meridional wind solution is a large northward crossequatorial surge during the January-March period when the meridional wind is usually weak (Fig. 3), so the modified forcing appears as a large southerly anomaly at this time. The result was an increase in upwelling near $1^{\circ} \mathrm{S}$ by about $0.5 \mathrm{~m} \mathrm{day}^{-1}$ and a strong northward cross-equatorial surface current. The effects on SST were strongest south of the equator, where the usual March SST maximum was reduced by about $1^{\circ} \mathrm{C}$, and weaker to the north, where the cooling was about $0.5^{\circ} \mathrm{C}$ or less (Fig. 16). Fixing the meridional winds also removed the April-May northward surge referred to by Mitchell and Wallace, which is due to a transient imbalance between northward wind stress and southward pressure gradient while the winds are accelerating (section $3 \mathrm{c} 2$ ). However, the associated difference in model SST was fairly small, no more than $0.6^{\circ} \mathrm{C}$, with a slight lag in the date of warmest SST (Fig. 16, top and middle). Little change in the TIW field or associated eddy advection was due to fixing the meridional winds.

\section{2) FIXED ZONAL WINDS}

Zonal winds have a profound effect on SST in the eastern equatorial Pacific because of the prominence of upwelling in the SST balance, because the zonal wind controls the slope and variability of the equatorial thermocline, and because the currents whose shear gives rise to the TIW are largely due to zonal winds. Rms changes in east Pacific SST due to removing the vari- ation of zonal winds were about $50 \%$ larger $\left(0.6^{\circ}-0.8^{\circ} \mathrm{C}\right)$ at all latitudes from $15^{\circ} \mathrm{S}$ to $11^{\circ} \mathrm{N}$ than seen in the fixed meridional wind experiment, and these were due to a more complicated mix of factors. In contrast to the fixed meridional wind run, fixing the zonal winds reduced the amplitude of the annual cycle of SST by more than a factor of 2 along the equator from about $90^{\circ}$ to at least $150^{\circ} \mathrm{W}$ but had little effect near South America.

Observed zonal winds are weaker than the mean during January-April and stronger than the mean in JuneNovember (Fig. 3). Suppressing this aspect of the forcing reduced the annual variation of the zonal currents and equatorial upwelling circulation. It also nearly eliminated thermocline depth variability, since the Kelvin waves that produce the major part of this variability in the east are driven by the zonal wind. Even though the wind speed felt by the model was not changed, the altered vertical shear and temperature gradient contributed to increasing cooling due to vertical mixing during the April-May period when the standard run is warming.

In this run, cooling due to upwelling was nearly constant all year. This represents a warming anomaly of more than $40 \mathrm{~W} \mathrm{~m}^{-2}$ during August-November when the standard case upwelling is strongest. However, the resulting warmer SST near the equator in boreal fall weakens the heating due to eddy advection associated with the TIW at that time of year, since the meridional temperature gradient is thereby smaller, and the SST front is weakened. These eddy terms are weaker by 30$40 \mathrm{~W} \mathrm{~m}^{-2}$ and partly compensate for the reduced upwelling in this run.

Without the variation of zonal wind, TIW continue throughout the year, unlike the standard run (and the observations) in which they are absent in boreal spring. This gives anomalous eddy warming during April-May in the fixed zonal wind experiment. These diverse influences result in the SST time series shown in Fig. 16, in which the SST annual cycle is reduced by about half in the upwelling region (bottom panel), but changes north of the equator are relatively smaller, about $0.5^{\circ} \mathrm{C}$ (although they are still larger than the changes associated with the fixed meridional wind run).

\section{3) FIXED CLOUd FRACTION}

Overall, removing the variation of cloudiness has a larger effect on the annual cycle of SST in the eastern equatorial Pacific than either of the two wind components described above, reducing the amplitude of annual variability by more than a factor of 2 over a wide region east of $110^{\circ} \mathrm{W}$ between $15^{\circ} \mathrm{S}$ and $15^{\circ} \mathrm{N}$, and along and north of the equator to about $140^{\circ} \mathrm{W}$. These anomalies are most pronounced north of the equator where the annual variation of cloudiness is largest (Fig. 12b). Note that the net forcing received at the sea surface (Fig. 12c) is much like the pure solar forcing (Fig. 12a) in the Southern Hemisphere but is strongly modified by cloud variations north of the equator. Figure 16 (top) shows 
that between $1^{\circ}$ and $4^{\circ} \mathrm{N}$, the run with fixed clouds develops a nearly pure semiannual cycle of SST, with differences of about $\pm 1.5^{\circ} \mathrm{C}$ from the standard run. Between the equator and $4^{\circ} \mathrm{S}$, the differences are comparable to those seen in the fixed zonal wind run, with a greatly reduced annual amplitude of SST.

Although the semiannual variation of SST seen just north of the equator when cloud fluctuations are suppressed (Fig. 16, top) might be interpreted as simply a direct response of SST to local semiannual solar forcing, examination of the regional SST balance terms shows a more complex picture. Changes in the vertical temperature gradient in this run lead to differences in vertical mixing and advection that are at least as large as those due to shortwave changes. Compared to the standard run, suppressing cloud variability in effect provides a cooling anomaly in the first half of the year and warming in the second. This reduces the SST increase during the usual spring warming, and maximum SST on the equator rises to only just above $24^{\circ} \mathrm{C}$, about $1{ }^{\circ} \mathrm{C}$ lower than in the standard run. The difference occurs only at the surface, so during boreal spring-summer, the vertical temperature gradient is much weaker than the standard run, and upwelling and vertical mixing are thereby less efficient at cooling the surface. Conversely, during boreal fall, SST in the fixed-cloud run is warmer than the standard case, the vertical temperature gradient becomes larger, and upwelling is then more efficient at cooling the surface. The pattern of lags that produce the SST fluctuations from these influences is complicated. Although we do not think the model vertical temperature gradient is perfectly realistic [see section $3 c(1)$ ], this type of interaction is plausible. This suggests that extremely simple interpretations of the SST balance (e.g., Schneider 1997) may not be adequate to diagnose the ocean response to varied forcing.

\section{Summary and discussion}

We have shown that the Gent and Cane (1989) sigmacoordinate ocean GCM, with the Chen et al. (1994a) hybrid mixing scheme, gives a reasonable simulation of many aspects of the observed annual cycle in the upper eastern tropical Pacific when forced with a smooth average annual cycle of observed winds and clouds. The model annual cycle of SST is broadly realistic; notable discrepancies from observations are that model SST annual amplitude in the east Pacific cold tongue is about $0.5^{\circ} \mathrm{C}(25 \%)$ too weak and its phase lags observations by about 1 month (Fig. 2). Mixed layer depth, changes of which are a crucial feature of the SST balance in this region, is well simulated in both its mean meridional profile and annual variability (Fig. 4). The model produces a tropical instability wave field that agrees with observations in frequency, amplitude, and seasonal modulation, as well as a northward surge in boreal spring that corresponds to the cross-equatorial current hypothesized by Mitchell and Wallace (1992) (Fig. 9).
Model mean currents are accurate in many respects (Fig. 5 ), including the magnitude of vertical velocity, and demonstrate an upwelling cell in the meridional plane that circulates roughly $15 \mathrm{~Sv}$ in the eastern tropical Pacific, varying between about 10 and $20 \mathrm{~Sv}$ over the year (total regional upwelling is about twice that, including contributions associated with the eastward diminishing of the equatorial undercurrent). This vertical-meridional flow is composed of two parts: zonal wind drives symmetric equatorial upwelling and surface divergence, while meridional wind produces a shallower cell with northward surface and southward subsurface flow, connected by up- and downwelling at $\pm 1^{\circ}-2^{\circ}$ latitude. The sum of these two gives upwelling centered south of the equator and northward cross-equatorial surface flow (Fig. 6). Variations of model zonal current and thermocline are less well simulated, developing a semiannual signal that is stronger than observed (Fig. 8) and an unrealistic steplike vertical temperature gradient in the thermocline (Fig. 5).

As previous investigators (Enfield 1986; Chang 1994) have found, the temperature balance in the surface layer in the eastern tropical Pacific is notoriously complicated, and in general, near the equator, virtually all terms are significant contributors to the model annual cycle (Fig. 11). Nevertheless, a streamlined description is possible. The largest terms of the annual cycle are the net solar flux (sun minus clouds, plus smaller terms) and equatorial upwelling. Upwelling transport doubles with the strongest wind speeds in July-October (Fig. 13), and this contributes much of the cooling as the cold tongue builds to its September-October maximum. Horizontal advection, particularly that associated with the annual modulation of tropical instability waves, is also a major influence. Warming due to tropical instability waves is largest in the second half of the year (Fig. 10) when upwelling is largest and equatorial SST is coolest, so the effect of this eddy mixing is to moderate the annual variation of cold tongue SST that would otherwise be caused by upwelling. One thinks of the entire upperequatorial circulation quickening when the winds are strongest in June-December; the westward South Equatorial Current and eastward North Equatorial Countercurrent are largest, as is equatorial upwelling. All three of these advective tendencies strengthen the SST front just north of the cold tongue. The strong horizontal currents produce largest meridional shear north of the equator at this time of year. This increased shear and stronger SST front both contribute to the development of tropical instability waves through barotropic and baroclinic instability processes, respectively (Philander 1978; Yu et al. 1995). The tropical instability waves then mix across the SST front, warming the equator (Fig. 14). Therefore, the June-December quickening generates opposing SST advective tendencies (upwelling vs eddy mixing), and despite many complicated features, the net oceanic effect on cold tongue SST is relatively small. The result is that the annual cycle of SST appears to follow the 
air-sea flux tendencies, but this appearance should not be interpreted as a one-dimensional balance.

Observing the westward expansion of the annual cold tongue, it is tempting to infer that this is due to cold water advected westward along the equator in the South Equatorial Current. However, low-frequency zonal gradients of SST are small (Fig. 1), and the SST balance shows that this is a relatively weak influence on the growth of the model cold tongue in the east. To further demonstrate this, an additional experiment was performed in which the forcing was as in the standard run, but an artificial wall extended $700 \mathrm{~km}$ west from the northern Peru coast, blocking the flow of coastally upwelled water onto the equator. Neither the mean nor the annual cycle of equatorial SST was much affected by the wall, showing that, in this model, the Peru upwelling region and equatorial cold tongue are distinct entities that evolve independently (at least as far as the ocean is concerned; coastal SST changes may modify the atmospheric circulation and affect the equator indirectly). Low-frequency meridional advection can be a larger term and at times represents a substantial cooling just north of the equator, but its annual variability is still several times smaller than that of upwelling in this model. The present results suggest that the particular crossequatorial flow hypothesized by Mitchell and Wallace (1992) does occur but has only modest effect on SST.

Poleward of about $4^{\circ}-5^{\circ}$ latitude, the SST balance is simpler than at the equator, and ocean advection and mixing terms have smaller effect on the model SST than does the air-sea flux (solar radiation modified by clouds and latent heat fluxes). In this model, the largest contribution of the ocean to the annual cycle of SST in most places more than a few degrees from the equator is due to changes of mixed layer depth, which controls how heating due to air-sea fluxes is distributed in the vertical.

Three altered forcing experiments illuminate the oceanic importance of the different features of atmospheric driving. In these experiments, the zonal and meridional wind and the cloud fraction were in turn fixed to their time mean values. Since the winds and clouds are coupled to at least some degree to the SST, it is not realistic to suppose that suppressing the variation of one of these would leave the others unchanged; however, these experiments point to the particular features of the ocean response that are associated with each aspect of atmospheric variation.

When the variability of meridional winds was suppressed, the northward pulse suggested by Mitchell and Wallace did not occur, but even in the region most affected by this advective cooling, the regionally averaged difference from the standard run was no more than about $0.6^{\circ} \mathrm{C}$, or roughly one-fifth of the annual cooling, and the amplitude of the annual cycle was unchanged (Fig. 16 , top). If this event is the key to the cold tongue onset, as Mitchell and Wallace argue, then it must be through an interaction with some other mechanism that enhances the effect, possibly a coupled feedback with stratus clouds. A complete resolution to this hypothesis awaits the analysis of observed time series of simultaneous SST and stratus clouds, as well as testing with atmospheric and coupled models.

Fixing the zonal wind resulted in relatively larger differences from the full-forcing run by reducing the annual variability of upwelling, thermocline depth, and tropical instability waves. However, since upwelling and tropical instability wave eddy advection tend to oppose each other, rms SST differences from the standard run were not too much larger than the constant meridional wind case (up to about $0.8^{\circ} \mathrm{C}$ ).

While the presentation here is in terms of a zonal average over the region, a clue to the relative importance of zonal and meridional winds is that the annual cycle of zonal winds propagates westward (Horel 1982), as does that of the SST (Fig. 2, right panels). Weakest zonal winds occur at about $93^{\circ} \mathrm{W}$ on 1 January, $97^{\circ} \mathrm{W}$ on 1 February, $110^{\circ} \mathrm{W}$ on $1 \mathrm{March}$, and $125^{\circ} \mathrm{W}$ on 1 April. These dates are very close to the dates of maximum observed SST (Fig. 2, top left). This correlation probably reflects an interaction in which the zonal pressure gradient in the atmospheric boundary layer is controlled by the SST gradient (Lindzen and Nigam 1987; Xie 1994). The annual cycle of meridional winds over the tropical Pacific does not propagate zonally, however. This timing suggests that variations of zonal wind are sufficient to produce the observed SST patterns, as the present model results also indicate, and that meridional winds are a secondary influence (though they may be involved in initiating the propagation in the east).

Fixing the cloud fraction gave a dramatically different picture, however, particularly north of the equator. Without the cloud fluctuations, the 1 cycle $\mathrm{yr}^{-1}$ variability that was seen in the standard run nearly disappeared, and SST variations became strongly semiannual north of the equator (Fig. 16, top). At and south of the equator, the annual cycle amplitude was reduced by half. Rms differences from the standard run were greater than $1{ }^{\circ} \mathrm{C}$ over a wide region in this experiment. Although much of the difference was simply due to the difference in net solar radiation, this signal was enhanced by changes in the vertical temperature gradient that affected the cooling efficiency of upwelling.

Variations of cloudiness are a key aspect of the model SST balance, especially east of $110^{\circ} \mathrm{W}$, where the convolution of sun and clouds results in a dominant 1 cycle $\mathrm{yr}^{-1}$ variation of net solar radiation received at the sea surface, not the semiannual forcing that would occur in the absence of clouds (Fig. 12). When clouds are taken into account, there is no paradox regarding semiannual forcing versus annual response in the eastern Pacific. Since the three-dimensional ocean advection terms tend to cancel each other, to first order the annual cycle of model upper-layer temperature change could be described as largely following the variation of cloud-modified net solar radiation (Fig. 15). Of course, cloud variations are probably intimately coupled to the local SST, 
so it is false to consider one of these as an external forcing for the other. Nevertheless, the value of the present results is to show that, even near the equator where the ocean advective signals are relatively intense, the terms associated with cloud variations are still among the largest influences on SST. That being the case, the unanswered question is how the coupled feedbacks work, both in the ITCZ, where convective clouds seem to have a negative feedback with SST, and under the stratus decks south of $5^{\circ} \mathrm{S}$, where a positive feedback occurs. Although the effect of cloud cover on SST can be at least partly understood, we know little about the sensitivity of the east Pacific stratus decks to the competing influences of SST and variability of the largescale subsidence in the overlying atmosphere. In any case, it is not possible to fully understand the annual cycle in the eastern Pacific from an ocean-only (as in the present work) or atmosphere-only (as in Mitchell and Wallace 1992) context.

Our conclusion that the ocean advective terms tend to cancel, and therefore SST tends to follow the net radiation, is partly consistent with an interpretation by Schneider (1997), who points out that time-integrating a (pure solar) forcing consisting of mixed 1 cycle $\mathrm{yr}^{-1}$ and semiannual variations tends to emphasize the lower frequency. He used a simple one-dimensional energy balance model to argue that complex processes need not be invoked to explain the 1 cycle $\mathrm{yr}^{-1}$ dominance of SST. Two distinctions from Schneider's conclusion are made. First, we find that in the present GCM, variations of cloudiness are an order (1) aspect of the net solar cycle, particularly north of the equator where the cloud variations are largest. Second, we find that variations of mixed layer depth have many ramifications in the SST budget, particularly in controlling the efficiency of upwelling to cool the SST. In agreement with many earlier studies, we find a complicated mixture of processes occurring in the ocean, often with small meridional scale near the equator. Correct simulation of these in an oceanic model will be necessary for successful coupled model studies. In general, our results do not point to a simplification as thorough as proposed by Schneider (1997).

Although many of our findings are model dependent, and different ocean models show different velocity fields and heat balances in this region, it is worth noting the degree to which our results can stand separate from the model details. First, the fundamental importance of cloudiness variations in the eastern Pacific shortwave forcing is based on (satellite) observations and bulk formulas. These formulas may be too simple to properly estimate the longwave loss due to the relatively warm temperature of stratus cloud tops, but this should not be sufficient to invalidate the conclusion. Similarly, we have noted that latent heat flux variations are less important in the eastern equatorial Pacific than they might seem, since weak winds (which imply weak evaporation) occur simultaneously with warm SST (which in- creases the efficiency of evaporation). This result again depends only on the accuracy of the observations and the realism of the bulk formula. Third, we have pointed to the cancellation between upwelling-induced cooling and tropical instability wave warming, both of which occur in the second half of the year. While the exact values we cite are model dependent, the overall tendency certainly occurs in nature. It has been stated that the TIW must not be a crucial element of the balance, since low-frequency models that do not develop these eddies still are capable of simulating a reasonable SST annual cycle. However, such models require a relatively high horizontal diffusivity, and this process will produce large mixing when the SST front north of the equator is strong, which is just when our model develops vigorous TIW. Whether these waves are explicitly resolved or merely parameterized, their role is to mix heat across the front in proportion to its strength, and that is exactly the timing that is observed.

Since the ocean in this region appears so sensitive to cloudiness variations, it would probably improve ocean models to evolve more sophisticated ways to use the additional details of cloud observations that are available from satellites, optical depth and cloud types, rather than simply overall cloud fraction as is usually done at present. Such an approach would require the development and testing of new parameterizations of the complex (and still only partly known) effects of clouds on long- and shortwave radiation. Very likely the different cloud types have different effects on the oceanic heating, and this may well lead to modification of conclusions reported here and elsewhere.

Acknowledgments. We gratefully acknowledge illuminating discussions with many colleagues, including Drs. D. E. Harrison, J. P. MacCrearie, M. J. McPhaden, D. W. Moore, E. S. Sarachik, and Z.-J. Yu. The assistance of Steve Hankin and the Ferret group at PMEL contributed greatly to our ability to dissect the model output. This research was supported by the NOAA's Pan American Studies Program.

\section{REFERENCES}

Brady, E. C., and P. R. Gent, 1994: The seasonal cycle of meridional heat transport in a numerical model of the Pacific equatorial upwelling zone. J. Phys. Oceanogr., 24, 2658-2673.

Bryden, H. L., and E. C. Brady, 1985: Diagnostic model of the threedimensional circulation in the upper equatorial Pacific Ocean. $J$. Phys. Oceanogr., 15, 1255-1273.

— , and — 1989: Eddy momentum and heat fluxes and their effects on the circulation of the equatorial Pacific Ocean. J. Mar. Res., 47, 55-79.

Chang, P., 1993: Seasonal cycle of sea surface temperature and mixed layer heat budget in the tropical Pacific Ocean. Geophys. Res. Lett., 20, 2079-2082.

_ 1994: A study of the seasonal cycle of sea surface temperature in the tropical Pacific Ocean using reduced gravity models. $J$. Geophys. Res., 99, 7725-7741.

__, and S. G. H. Philander, 1994: A coupled ocean-atmosphere 
instability of relevance to the seasonal cycle. J. Atmos. Sci., $\mathbf{5 1}$ 3627-3648.

Chen, D., L. M. Rothstein, and A. J. Busalacchi, 1994a: A hybrid vertical mixing scheme and its application to tropical ocean models. J. Phys. Oceanogr., 24, 7725-7741.

—, A. J. Busalacchi, and L. M. Rothstein, 1994b: The roles of vertical mixing, solar radiation and wind stress in a model simulation of the sea surface temperature seasonal cycle in the tropical Pacific Ocean. J. Geophys. Res., 99, 20 345-20 359.

Donoso, M. C., J. E. Harris, and D. B. Enfield, 1994: Upper ocean thermal structure of the eastern tropical Pacific. NOAA Tech. Rep. ERL 450-AOML 36, NOAA/AOML, Miami, FL.

Enfield, D. B., 1986: Zonal and seasonal variability of the equatorial Pacific heat balance. J. Phys. Oceanogr., 16, 1038-1054.

Gent, P. R., and M. A. Cane, 1989: A reduced gravity, primitive equation model of the upper equatorial ocean. J. Comput. Phys., 81, 444-480.

Giese, B. S., and J. A. Carton, 1994: The seasonal cycle in a coupled ocean-atmosphere model. J. Climate, 7, 1208-1217.

Gordon, C., and R. A. Corry, 1991: A model simulation of the seasonal cycle in the tropical Pacific ocean using climatological and modeled surface forcing. J. Geophys. Res., 96, 847-864.

Halpern, D., and H. P. Freitag, 1987: Vertical motion in the upper ocean of the equatorial eastern Pacific. Oceanol. Acta, 6 (SP), 19-26.

- R. A. Knox, and D. S. Luther, 1988: Observations of 20-day period meridional current oscillations in the upper ocean along the Pacific equator. J. Phys. Oceanogr., 18, 1514-1534.

Hansen, D., and C. Paul, 1984: Genesis and effects of long waves in the equatorial Pacific. J. Geophys. Res., 89, $10431-10440$.

Harrison, D. E., 1991: Equatorial sea surface temperature sensitivity to net surface heat flux. J. Climate, 4, 539-549.

Hayes, S. P., P. Chang, and M. J. McPhaden, 1991a: Variability of sea surface temperature in the eastern equatorial Pacific during 1986-1988. J. Geophys. Res., 96, 10 553-10 566.

- , L. J. Mangum, J. Picaut, A. Sumi, and K. Takeuchi, 1991b: TOGA-TAO: A moored array for real-time measurements in the tropical Pacific Ocean. Bull. Amer. Meteor. Soc., 72, 339-347.

Horel, J. D., 1982: On the annual cycle of the tropical Pacific atmosphere and ocean. Mon. Wea. Rev., 110, 1863-1878.

Kessler, W. S., and M. J. McPhaden, 1995: The 1991-93 El Niño in the central Pacific. Deep-Sea Res., 42, 295-333

- M. C. Spillane, M. J. McPhaden, and D. E. Harrison, 1996 Scales of variability in the equatorial Pacific inferred from the TAO buoy array. J. Climate, 9, 2999-3024.

Koberle, C., and S. G. H. Philander, 1994: On the processes that control seasonal variations of sea surface temperature in the tropical Pacific Ocean. Tellus, 46A, 481-496.

Kraus, E. B., and J. S. Turner, 1967: A one-dimensional model of the seasonal thermocline. II: The general theory and its consequences. Tellus, 19, 98-105.

Levitus, S., 1982: Climatological Atlas of the World Ocean. NOAA
Prof. Paper 13, U.S. Government Printing Office, Washington, DC, $173 \mathrm{pp}$

Li, T., and S. G. H. Philander, 1996: On the annual cycle of the eastern equatorial Pacific. J. Climate, 9, 2986-2998.

Lindzen, R. S., and S. Nigam, 1987: On the role of sea surface temperature variations in forcing low-level winds and convergence in the tropics. J. Atmos. Sci., 44, 2418-2436.

McPhaden, M. J., 1993: TOGA-TAO and the 1991-93 El NiñoSouthern Oscillation. Oceanography, 6, 36-44.

Mitchell, T. P., and J. M. Wallace, 1992: The annual cycle in equatorial convection and sea surface temperature. J. Climate, 5, 11401156.

Murtugudde, R., and A. J. Busalacchi, 1998: Salinity effects in tropical oceans. J. Geophys. Res., in press.

Philander, S. G. H., 1978: Instabilities of zonal equatorial currents, Part 2. J. Geophys. Res., 83, 3679-3682.

- , and P. Delecluse, 1983: Coastal currents in low latitudes (with application to the Somali and El Niño currents). Deep-Sea Res., 30, 887-902.

Price, J. F., R. A. Weller, and R. Pinkel, 1986: Diurnal cycling: Observations and models of the upper ocean response to diurnal heating cooling and wind mixing. J. Geophys. Res., 91, 84118427.

Pullen, P. E., R. L. Bernstein, and D. Halpern, 1987: Equatorial longwave characteristics determined from satellite sea surface temperature and in situ data. J. Geophys. Res., 92, 742-748.

Qiao, L., and R. H. Weisberg, 1996: The zonal momentum balance of the equatorial undercurrent in the central Pacific. J. Phys. Oceanogr., 27, 1094-1119.

Reed, R. K., 1977: On estimating insolation over the ocean. J. Phys. Oceanogr., 7, 482-485.

Reynolds, R. W., and T. M. Smith, 1994: Improved sea surface temperature analysis using optimum interpolation. J. Climate, 7, 929-948.

Rossow, W. B., and R. A. Schiffler, 1991: ISCCP cloud data products. Bull. Amer. Meteor. Soc., 72, 2-20.

Seager, R., S. E. Zebiak, and M. A. Cane, 1988: A model of the tropical Pacific sea surface temperature climatology. J. Geophys. Res., 93, 1265-1280.

—, Y. Kushnir, and M. A. Cane, 1995: On heat flux boundary conditions for ocean models. J. Phys. Oceanogr., 25, 3219-3230.

Stricherz, J., J. J. O'Brien, and D. M. Legler, 1992: Atlas of Florida State University tropical Pacific Winds for TOGA 1966-1985. Florida State University, 275 pp.

Wyrtki, K., 1981: An estimate of equatorial upwelling in the Pacific. J. Phys. Oceanogr., 11, 1205-1214.

- and G. Eldin, 1982: Equatorial Upwelling events in the central Pacific. J. Phys. Oceanogr., 12, 984-988.

Xie, S. P., 1994: On the genesis of the equatorial annual cycle. $J$. Climate, 7, 2008-2013.

Yu, Z., J. P. McCreary, and J. A. Proehl, 1995: Meridional asymmetry and energetics of tropical instability waves. J. Phys. Oceanogr., 25, 2997-3007. 